\title{
Tuning the sub-processes in laser reduction of graphene oxide by adjusting the power and scanning speed of laser
}

Zhengfen Wan ${ }^{\text {a, b }}$, Shujun Wang ${ }^{\text {a, b }}$, Ben Haylock ${ }^{\text {c }}$, Jasreet Kaur ${ }^{\text {a }}$, Philip Tanner ${ }^{\text {a }}$, David Thiel ${ }^{\text {b }}$,

\author{
Robert Sang ${ }^{\mathrm{c}}$, Ivan S Cole ${ }^{\mathrm{d}}$, Xiangping Li ${ }^{\mathrm{e}}$, Mirko Lobino ${ }^{\mathrm{a}, \mathrm{c}}$, Qin Li ${ }^{\mathrm{a}, \mathrm{b}, *}$ \\ ${ }^{a}$ Queensland Micro- and Nanotechnology Centre, Griffith University, Nathan, QLD 4111, Australia \\ ${ }^{b}$ School of Engineering and Built Environment, Griffith University, Nathan, QLD 4111, Australia \\ ${ }^{c}$ Centre for Quantum Dynamics, Griffith University, Nathan, QLD 4111 Australia \\ ${ }^{d}$ Advanced Manufacturing and Fabrication, RMIT University, Melbourne, VIC 3000, Australia \\ ${ }^{e}$ Institute of Photonics Technology, Jinan University, Guangzhou 510632, China
}

\begin{abstract}
Laser reduction of graphene oxide is a promising technology for manufacturing advanced devices such as supercapacitors, sensors and transistors, owing to its distinctive advantages in selective and localized GO reduction, direct micro- nanoscale patterning, and no requirement for chemicals. However, the fundamental mechanism underlying the laser induced reduction is still not well understood. In this paper, we demonstrate that by adjusting the power and scanning speed of a $780 \mathrm{~nm}$ femtosecond laser, not only can one distinguish, but also effectively tune, two coexisting sub-processes during the laser reduction, namely the direct conversion from $\mathrm{sp}^{3}$ to $\mathrm{sp}^{2}$
\end{abstract}


carbon and removal of oxygen functional groups. Different oxygen containing groups demonstrate varied degrees of reduction when the power of the laser was varied. Our study provides solid and direct evidence for the coexistence of two sub-processes in the laser induced reduction of graphene oxide, which is essential for both mechanistic understanding and practical adoption of this technique in real word applications.

\section{Introduction}

Graphene has become one of the major interesting research subjects following its discovery in $2004[1,2]$ due to its high electrical and thermal conductivities, optical transparency, and exceptional mechanical strength, making it a promising candidate for many applications including transparent electrodes [3], capacitors [4], sensors [5] transistors and memory devices [6]. Different preparation methods of graphene have been studied extensively, with the most popular ones being mechanical exfoliation [7], epitaxial growth [8], chemical vapor deposition (CVD) $[9,10]$ and the reduction of graphene oxide (GO) [11]. As a mainstream precursor for reduced graphene, GO has a single- or multilayer atomic structure which consists of carbon skeletons bearing a resemblance to graphene but being decorated with oxygen containing groups and defects. GO can be partially converted into graphene sheets by removing its oxygen-containing groups via thermal [12], chemical [13], microwave [14], plasma [15], photo [16-19], or laser reduction [20-25]. Compared to other methods, GO reduction has great potential for mass production of graphene since GO can be produced from graphite on a large scale with 
cost-effective chemical methods [26]. Moreover, it can naturally form stable aqueous colloids due to its high hydrophilicity [27], which is a desirable property for applications that require solution processing.

Compared to the thermal, chemical or plasma reduction of GO, the laser reduction method demonstrates several unique advantages, including selective and localized treatment, sub-micron feature size (down to several hundred nanometers [28]), no requirement for chemicals or heating equipment, and convenient and flexible patterning compatibility [29]. Therefore, laser reduction of GO thin film is ideal in several applications including supercapacitors [30-32], sensors [33-35], and field transistors [36], whereby reduction and device patterning can be achieved simultaneously. Lasers with various wavelengths (248 nm [37], $800 \mathrm{~nm}$ [38], $10.6 \mu \mathrm{m}$ [39]) and different pulse durations (continuous wave, nanosecond [40], picosecond [41], femtosecond (fs) [42]) have been used to perform the reduction. Kaner's group demonstrated a scalable fabrication of supercapacitors by laser direct-writing on GO films and more than 100 micro-supercapacitors were produced in less than 30 minutes [43], illustrating an enormous potential for roll-to-roll production.

However, so far the fundamental mechanism of laser reduction of GO is not yet fully understood, which is essential to tune and optimize the properties of laser reduced graphene oxide (LRGO) for real applications. In limited reports on the mechanism of laser reduction investigated by a few research groups [28, 40, 44, 45], the proposed mechanisms could be divided into three categories: sole photothermal driven conversions [44], sole photochemical driven conversions [28] and coexistent photothermal- and photochemical driven conversions [40, 
45]. In the photothermal theory, the laser reduction of GO results from the thermal effects induced by the laser, namely, the oxygen functional groups are removed because of localized high temperatures. In the photochemical theory, the laser reduction of GO is attributed to a direct breakage of the chemical bonds between the carbon and oxygen atoms (such as $\mathrm{C}-\mathrm{O}$ or $\mathrm{C}=\mathrm{O}$ ) resulting in the removal of the oxygen. A recent report from Arul et al. proposed that the reduction takes place in two processes, namely the photochemical removal of oxygen by photochemical process, and the photothermal conversion of reduced carbon into $\mathrm{sp}^{2}$ graphene structure [40]. Nevertheless, it is difficult to accurately and directly prove whether the temperature induced by the laser is higher than the thresholds for initiating the reduction of GO. Considering the possible multiphoton absorption in the process, the threshold of laser wavelength for photochemical effect is also ambiguous. Moreover, the involvement of the photochemical and photothermal effects in the oxygen removal and conversion of $\mathrm{sp}^{3}$ carbon into $\mathrm{sp}^{2}$ carbon is still unclear. Detailed study of the reduction effects on different oxygen containing groups is absent. Therefore, a systematic study is needed for connecting the dots to provide a better understanding of the overall process.

This study provides a systematic investigation on the mechanism of laser reduction. The GO film is reduced by a femtosecond (fs) laser (780 nm wavelength; 70 fs pulse width; $50 \mathrm{MHz}$ repetition rate) with different laser power and scanning speeds. After the laser treatment, optical microscopy, surface profiling, scanning electron microscopy (SEM), Raman spectroscopy, x-ray photoelectron spectroscopy (XPS) and x-ray diffraction (XRD) were employed for characterizing the carbon structures. Our results confirm that the reduction process consists of two adjustable 
fundamental sub-processes depending on laser power and scanning speed: the conversion of $\mathrm{sp}^{3}$ carbon to $\mathrm{sp}^{2}$ carbon and the removal of oxygen functional groups. At lower power of $3 \mathrm{~mW}$ (fluence $1.9 \mathrm{~mJ} \mathrm{~cm}^{-2}$ ), there is clear conversion of $\mathrm{sp}^{3}$ carbon $(20.99 \%)$ to $\mathrm{sp}^{2}$ carbon, while the percentage of oxygen containing groups only decreases by $5.17 \%$. Increasing the laser power up to $13 \mathrm{~mW}$ (fluence $8.3 \mathrm{~mJ} \mathrm{~cm}^{-2}$ ), we observe a reduction in oxygen containing groups of $13.28 \%$, together with the distinctive conversion of $\mathrm{sp}^{3}$ carbon to $\mathrm{sp}^{2}$ carbon, indicating a dependence of these two sub-processes on the laser power. Furthermore, different oxygen containing groups demonstrate varied degree of reduction for the same laser power. An obvious decrease in the percentage of $\mathrm{C}=\mathrm{O}$ is noticed at a laser power of $3 \mathrm{~mW}$, while that of $\mathrm{C}-\mathrm{O}$ is not observed until the laser power reaches to $13 \mathrm{~mW}$. The $\mathrm{COOH}$ group does not show a distinctive decrease with laser power from 3 to $13 \mathrm{~mW}$. We also demonstrate that the degree of reduction, the decrease of thickness of LRGO and the conductivity of LRGO can be modulated by adjusting the laser power and its scanning speed. These findings provide a better understanding of the fundamental mechanism underpinning laser reduction as well as an insight to how to effectively tune the properties of LRGO.

\section{Experiment}

\subsection{Method}

GO was synthesized with modified Hummers method [46]. The glass wafer was cleaned with acetone, ethanol and then pure water with the aid of ultrasound. After cleaning, the glass 
was treated with Piranha solution $\left(7: 398 \% \mathrm{H}_{2} \mathrm{SO}_{4}: 30 \% \mathrm{H}_{2} \mathrm{O}_{2}\right)$ and dried at $60{ }^{\circ} \mathrm{C}$ in air before use. The GO dispersed in water at a concentration of $2.4 \mathrm{~g} / \mathrm{L}$ was spin-coated at $1000 \mathrm{rpm}$ for 1 minute on the glass wafer, dried at $60{ }^{\circ} \mathrm{C}$ and the process was repeated 4 times. The thickness of GO film is $110 \mathrm{~nm}$. A fs pulse laser with $780 \mathrm{~nm}$ center wavelength (70 fs pulse width, $50 \mathrm{MHz}$ repetition rate, spot size of $2 \mu \mathrm{m}$ diameter) was employed for GO reduction. The laser power was adjusted from 3 to $13 \mathrm{~mW}$ (equivalent laser fluence ranging from 1.9 to $8.3 \mathrm{~mJ} \mathrm{~cm}^{-2}$ ). The source laser is a custom-made erbium-doped fiber cavity laser. The laser is focused with a Newport M-40X objective lens with effective focal length of $4.5 \mathrm{~mm}$. The micromachining stage is the Newport laser uFAB microfabrication workstation. The laser treatment on GO film is carried out in ambient conditions.

The samples for conductivity test were fabricated with the following procedures: the GO film was spin-coated on glass wafer. The gold electrodes were sputtered on the top of the GO film with a gap of about $600 \mu \mathrm{m}$. Subsequently, a LRGO wire was laser-written to connect the two electrodes.

\subsection{Characterizations}

Raman spectra were acquired with Raman Spectrometer Renishaw Invia (using $514 \mathrm{~nm}$ excitation wavelength and a 50x objective, acquisition parameters: $0.05 \mathrm{~mW}$ power, $10 \mathrm{~s}$ exposure time, 1 accumulation, and 2400 1/m gridding). Peak fitting of the Raman data was carried out using the WiRE3.3 software. X-ray photoelectron spectroscopy (XPS) was performed with Kratos Axis ULTRA X-ray Photoelectron Spectrometer. The peak fitting of the XPS data 
was carried out using the CasaXPS software. The XRD data were collected with Rigaku SmartLab with $\mathrm{Cu} \mathrm{K} \alpha$ radiation $(\lambda=1.54 \AA)$. The optical micrographs were obtained with a microscope from ProSciTech, camera UCMOS05100KPA. The SEM images were acquired with JEOL JSM-7001F. The thickness of the films was measured with Dektak 150 surface profiler. The film resistance was measured with a two-probe tester, Model 6430 source meter (Keithley Instruments Inc., USA).

\section{Results and discussion}

The schematic in Figure 1(a) illustrates a fs pulsed laser with central wavelength at $780 \mathrm{~nm}$ is employed to reduce the GO film (thickness approximately $110 \mathrm{~nm}$ ) fabricated on glass substrate.

For studying the effects of laser power and scanning speed, an array of LRGO rectangle spots have been directly written by the laser irradiation to allow a systematic study. The inset shows an optical microscopic image of LRGO array, demonstrating that these LRGO rectangles treated with various power of laser and scanning speed show varied optical contrast, which may result from different reduction degrees by the laser [47]. The SEM image in Figure 1(b) shows that the laser scanned area is brighter due to the abundant emission of secondary electrons [48]. The optical image displayed as an inset in Figure 1(b) shows the laser scribed Griffith University logo, illustrating the flexibility of this technique in pattern creation. The smallest feature size of LRGO with the employed laser is about $2 \mu \mathrm{m}$ in diameter. As shown, the laser writing technology is highly flexible and straightforward for patterning, very applicable for micro-device 
fabrication. The magnified SEM images of GO and LRGO displayed in Figure 1(c) show that there is no discernible modification on the morphology of film after the laser treatment.

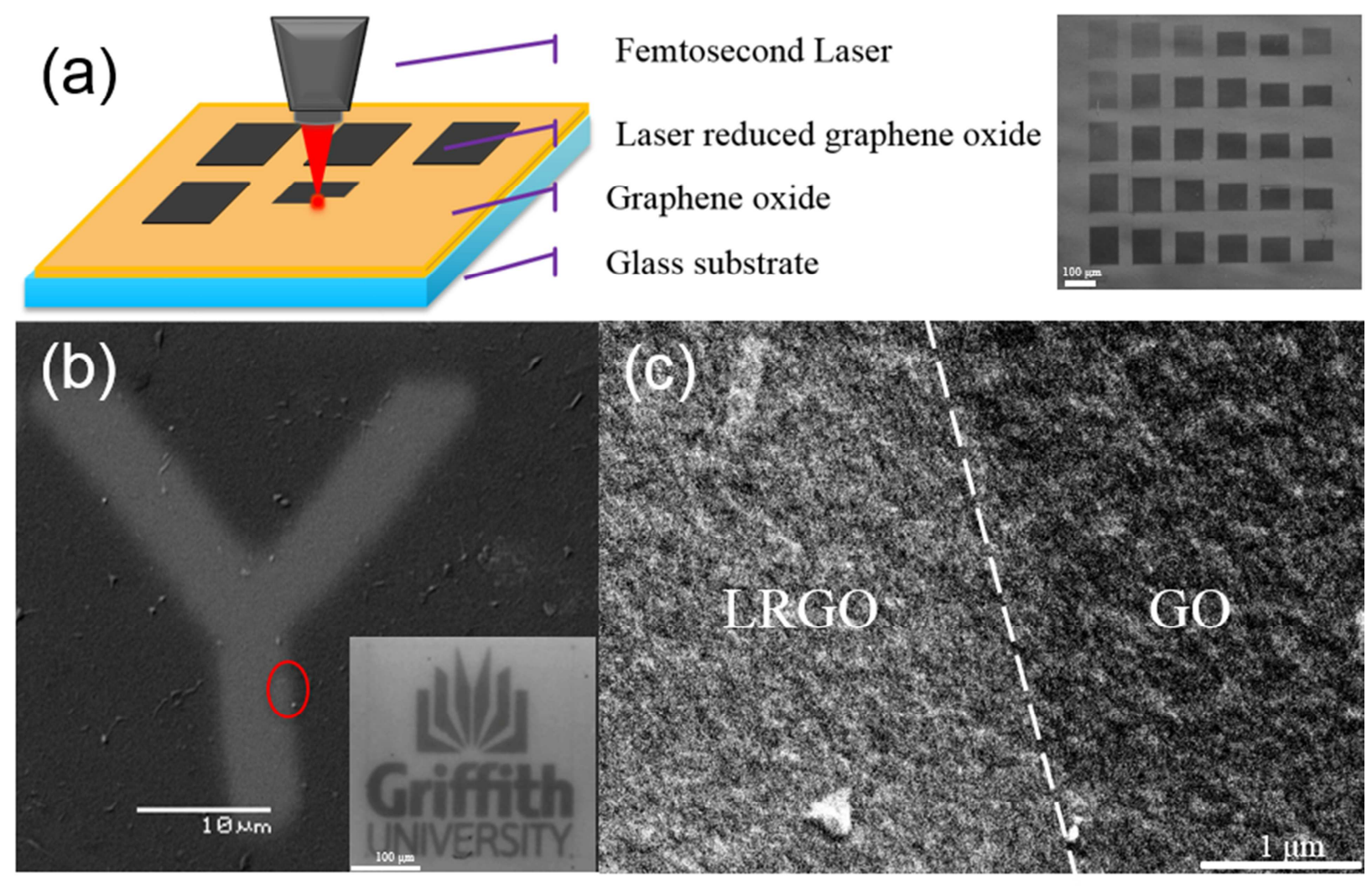

Figure 1 (a) Schematic figure of laser reduction of GO film. The inset shows the microscopic image of GO treated with varied power of laser and scanning speed, scale bar $100 \mu \mathrm{m}$. (b) The SEM images of the GO treated with laser, scale bar $10 \mu \mathrm{m}$. The inset shows Griffith University logo under microscopy, scale bar $100 \mu \mathrm{m}$. (c) The enlarged SEM image of GO and LRGO, scale bar $1 \mu \mathrm{m}$.

\subsection{The influence of fs laser parameters on the degree of reduction}

To understand the influence of the fs laser parameters on the extent of the GO reduction, XPS and Raman spectroscopy were performed to understand the carbon bonding structure and the change in oxygen quantity and chemical composition. Figure S2 displays the survey XPS of GO and LRGOs fabricated with various laser powers $(3 \mathrm{~mW}, 5 \mathrm{~mW}, 7.5 \mathrm{~mW}, 10 \mathrm{~mW}, 13 \mathrm{~mW})$ at 
scanning speed of $5 \mu \mathrm{m} / \mathrm{s}$, showing the presence of carbon and oxygen atoms. With increased laser power, it is observed that the intensity of $\mathrm{C} 1 \mathrm{~s}$ peak is significantly increased, while that of the O1s peak decreased, indicating a loss of oxygen atoms. The atomic carbon to oxygen ratios $(\mathrm{C} / \mathrm{O})$ was calculated based on the area of the peaks of $\mathrm{C} 1 \mathrm{~s}$ and $\mathrm{O} 1 \mathrm{~s}$ spectra. Figure 2(a) shows the dependence of $\mathrm{C} / \mathrm{O}$ on laser power; There is a clear trend of increasing $\mathrm{C} / \mathrm{O}$ from 2.46 (GO) to 3.35 (LRGO $13 \mathrm{~mW}$ ) with the increased laser power, which illustrates that the amount of oxygen functional groups in LRGO can be adjusted by the laser power.

A closer inspection on the acquired XPS and Raman spectra revealed more details on the defects and structure of the LRGOs. The Raman spectra of LRGO samples fabricated with various laser power (from 3 to $13 \mathrm{~mW}$ ) and laser scanning speed (from 0.1 to $5 \mu \mathrm{m} / \mathrm{s}$ ) were acquired. Figure 2(b) presents the Raman spectra of GO and LRGO $(7.5 \mathrm{~mW}, 0.2 \mu \mathrm{m} / \mathrm{s})$ with their fitting lines, including $\mathrm{D}, \mathrm{G}$ and $\mathrm{N}$ (non-crystalized $\mathrm{sp}^{2}$ ) bands. The D-band $\left(1355 \mathrm{~cm}^{-1}\right)$ results from defects in the plane structure of graphite due to the presence of oxygen containing groups, while the G-band $\left(1604 \mathrm{~cm}^{-1}\right)$ is attributed to an E2g mode of graphite associated with the stretching motion of $\mathrm{sp}^{2}$ carbon atoms $[49,50]$. Both $\mathrm{D}$ and $\mathrm{G}$ bands originate from different vibrational modes of graphitic structures, while the $\mathrm{N}$ band $\left(1540 \mathrm{~cm}^{-1}\right)$ is due to the amorphous $\mathrm{sp}^{2}$ carbon. The shape of those peaks depends on the crystallite size; when the crystallites become larger, the peaks become narrower $[51,52]$. The band intensity ratio $\mathrm{I}_{\mathrm{D}} / \mathrm{I}_{\mathrm{G}}$ reflects the degree of disorder in the graphene-structure [53]. As shown in Table S2, the crystalline size in the axis (La) can be obtained from $\mathrm{I}_{\mathrm{D}} / \mathrm{I}_{\mathrm{G}}$ using the equation [54]:

$$
\operatorname{La}(\mathrm{nm})=\left(2.4 \times 10^{-10}\right) \times \lambda_{\iota}^{4} \times\left(\frac{I_{D}}{I_{G}}\right)^{-1}
$$


where $\lambda_{l}$ is the wavelength of the Raman laser $\left(\lambda_{\iota}=514 \mathrm{~nm}\right)$.

Figure S3(a) shows the Raman spectra of GO and LRGOs fabricated at laser scanning speed from 0.1 to $5 \mu \mathrm{m} / \mathrm{s}$ with constant laser power of $5 \mathrm{~mW}$. At the laser power of $5 \mathrm{~mW}$, a decrease of the $I_{D} / I_{G}$ ratio can be observed with a decrease in the scanning speed. Figure $S 3(b)$ displays the Raman spectra of GO and LRGOs fabricated at laser scanning speed of $0.2 \mu \mathrm{m} / \mathrm{s}$ with laser power increased from 3 to $13 \mathrm{~mW}$, which shows a consistent decrease of the $\mathrm{I}_{\mathrm{D}} / \mathrm{I}_{\mathrm{G}}$ ratio with the increase of the laser power. This decrease of $\mathrm{I}_{\mathrm{D}} / \mathrm{I}_{\mathrm{G}}$ illustrates a successful reduction of GO, resulting in fewer defects and larger crystalline size. Figure S3(c-d) show the Raman spectra of LRGO (13mW, $0.2 \mu \mathrm{m} / \mathrm{s})$ with 10 accumulations (c) and 30 accumulations (d). The 2D Raman band $\left(2700 \mathrm{~cm}^{-1}\right)$ is the second order of zone-boundary phonons [55]. Both graphene and graphite demonstrate strong 2D peak, while graphene oxide does not feature such an obvious 2D peak. After the $780 \mathrm{~nm}$ fs laser treatment of the GO, the 2D band did not appear, which suggests that the fs laser reduction is localized and does not develop large planar sheet of graphene.More comprehensive results of the $I_{D} / I_{G}$ dependence on laser power and scanning speed are shown in Figure 2(c) and Table S3. Five spots of each LRGO sample were measured with small variation of $\mathrm{I}_{\mathrm{D}} / \mathrm{I}_{\mathrm{G}}$, illustrating its good consistency and uniform. After laser reduction, the $\mathrm{I}_{\mathrm{D}} / \mathrm{I}_{\mathrm{G}}$ ratio decreased from 1.37 (for GO) to 1.13 (for LRGO $13 \mathrm{~mW}, 0.1 \mu \mathrm{m} / \mathrm{s}$ ). Figure 2(c) demonstrates the tendency that higher laser power combined with lower scanning speed results in a reduced $\mathrm{I}_{\mathrm{D}} / \mathrm{I}_{\mathrm{G}}$ value, which illustrates the adjustable defects density and structure of LRGO.

Figure 2(d) shows the $I_{D} / I_{G}$ versus energy density (laser energy density = laser power/(scanning speed $\times$ track width) at different laser power. It can be noticed that at a constant laser power, with 
an increase in the laser energy density, namely slower scanning speed, the value of $\mathrm{I}_{\mathrm{D}} / \mathrm{I}_{\mathrm{G}}$ decreases until it becomes saturated. With the increase of the laser power, the $I_{D} / I_{G}$ value saturates at relatively lower energy density and reaches a lower value. It can be concluded that the laser power (fluence) plays a decisive role on the $\mathrm{I}_{\mathrm{D}} / \mathrm{I}_{\mathrm{G}}$ change, while the energy density can also affect it to some extent. The results correlated with energy density provides a more general guidance to modulate the properties of LRGO by changing the parameters of the laser. It is worth noting that since GO can be reduced even under ambient conditions due to long exposure to room light [56], the contrast between the laser-reduced areas and the un-reduced areas of a GO film could decrease. For its stability and reliability in applications, the GO treated with laser should be encapsulated with protection to avoid the further reduction.

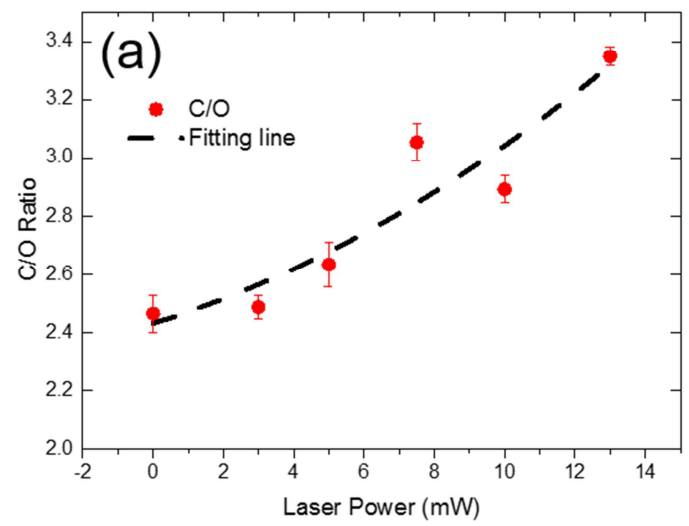

(c)

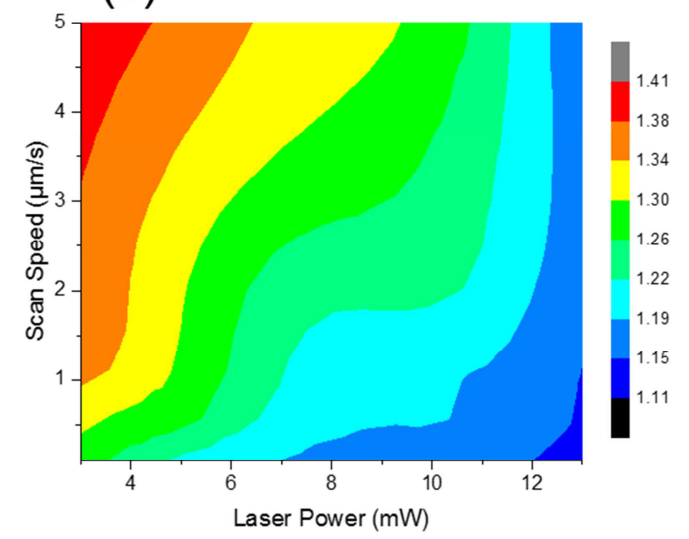

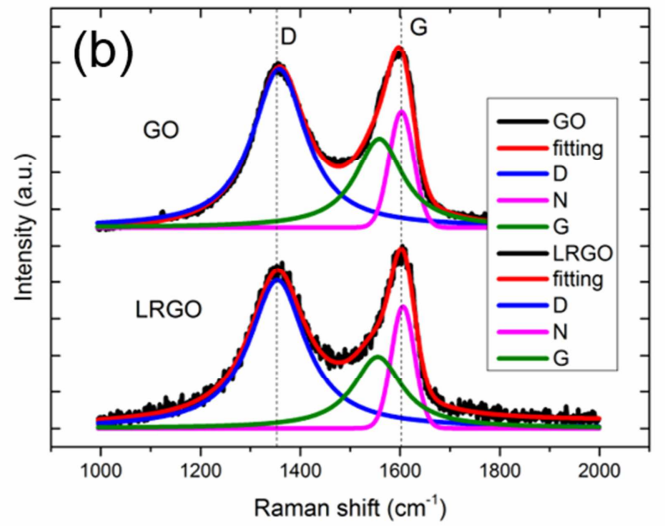

(d)

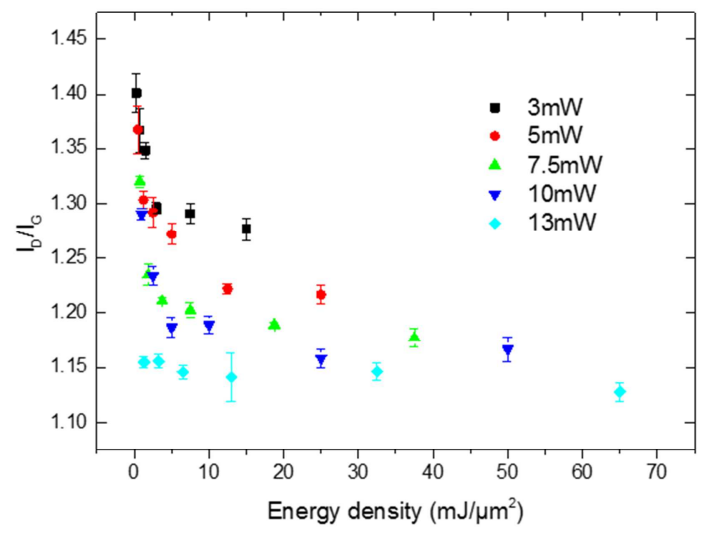


Figure 2 (a) The C/O ratio of GO and LRGOs fabricated with laser power of $3 \mathrm{~mW}, 5 \mathrm{~mW}, 7.5 \mathrm{~mW}, 10 \mathrm{~mW}$ and $13 \mathrm{~mW}$. (b) The Raman spectra of GO and LRGO (7.5 mW, $0.2 \mu \mathrm{m} / \mathrm{s})$ and the fitted curve. (c) The dependence of $I_{D} / I_{G}$ of $L R G O$ on laser power and laser scanning speed. (d) The dependence of $I_{D} / I_{G}$ on energy density and laser power.

\subsection{The modulation of the thickness of laser reduced graphene oxide}

After irradiation, the film thickness was measured with surface profiler and the dependence of decreased thickness on energy density calculated from the laser power (3-13 $\mathrm{mW})$ and laser scanning speed $(0.1,0.2$ and $0.5 \mu \mathrm{m} / \mathrm{s})$ is shown in Figure 3. The inset of Figure 3 shows the schematic of the cross section of GO film during laser irradiation. The thickness of LRGO decreases with increased laser energy density but saturates at the energy density of $37.5 \mathrm{~mJ}$ $\mu \mathrm{m}^{-2}$. The thickness decrease can be adjusted from $20 \%(22 \mathrm{~nm})$ to $70 \%(77 \mathrm{~nm})$ of its original thickness, namely $110 \mathrm{~nm}$, by modulating the laser energy density. This reduction of thickness likely results from the mass loss from the GO film and the laser induced ablation [38]. For relatively high scanning speed $(>1 \mu \mathrm{m} / \mathrm{s}$ ), the thickness decrease is indistinguishable by the Surface Profiler. This suggests that when the laser energy density is high (scanning speed is low), there may be higher thermal effect, which results in laser ablation effect. In terms of technology capability, this result demonstrates that in addition to 2-dimensional (2D) patterning, the laser reduction can also simultaneously introduce 3 dimensional (3D) features that are adjustable by the laser parameters. 


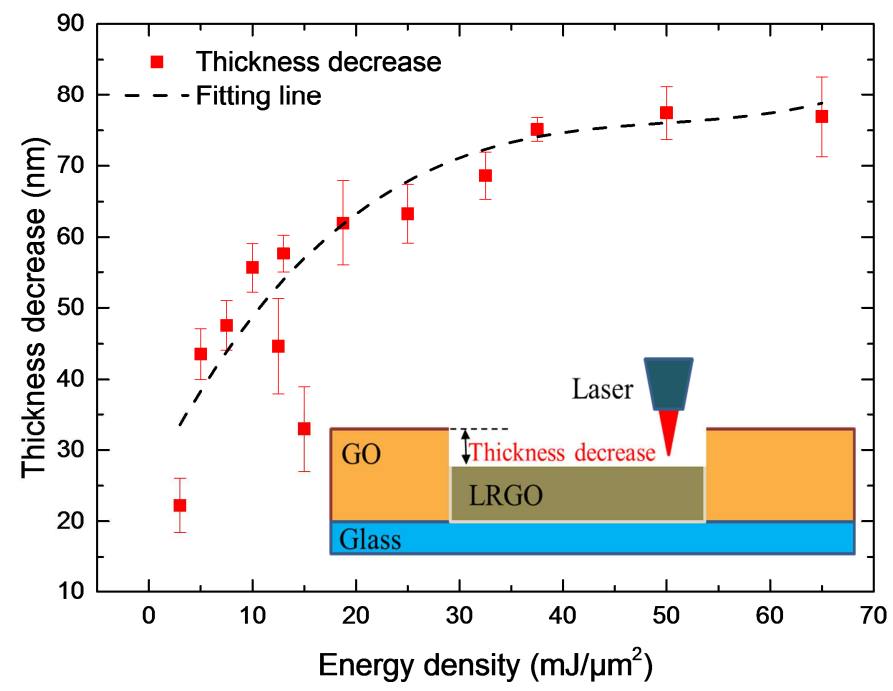

Figure 3 The dependence of thickness decrease on the laser energy density, the inset is the schematic depicting the cross section of a GO film under laser treatment.

\subsection{The conductivity of laser reduced graphene oxide}

After irradiation, the conductivity of the LRGO is improved compared to that of GO. The laser power was kept at $5 \mathrm{~mW}$ with scanning speed varied from 0.1 to $5 \mu \mathrm{m} / \mathrm{s}$. Figure 4 displays the dependence of conductivity on laser energy density. The inset shows schematic figure of conductivity test (left) and the microscopic image of a LRGO line between two Au electrodes for the conductivity test (right). Before laser treatment, the conductivity of GO is about $10^{-3} \mathrm{~S} / \mathrm{m}$. After laser reduction, the conductivity of LRGO was improved to $45.5 \mathrm{~S} / \mathrm{m}$ under scanning speed of $0.1 \mu \mathrm{m} / \mathrm{s}$, that is 4 orders of magnitude greater than that of GO. With different laser scanning speeds, the conductivity of LRGO varies from 19 to $45.5 \mathrm{~S} / \mathrm{m}$.

It's worth noting that the conductivity of LRGO in the various reports $[30,53,57,58]$ ranged from from $10^{1}$ to $10^{4} \mathrm{~S} / \mathrm{m}$, with the highest reported value of $2.56 \times 10^{4} \mathrm{~S} / \mathrm{m}$ [50]. One reason 
for this high variation of the LRGO conductivity could be the different qualities of the starting GO, which shows conductivities ranging from $10^{-4}$ to $10^{1} \mathrm{~S} / \mathrm{m}[41,57,59]$. During GO film fabrication, GO flakes stack and the resistance between stacked layers plays a significant role in the overall film resistance [60]. The other reason could be the different reduction degree of GO. Strong et al. demonstrated high reduction degree with a high $\mathrm{C} / \mathrm{O}$ ratio at 27.8 , enhancing the conductivity from $6.6 \times 10^{-3} \mathrm{~S} / \mathrm{m}(\mathrm{GO})$ to $1.65 \times 10^{3} \mathrm{~S} / \mathrm{m}(\mathrm{LRGO})$ [34]. Since the conductivity of GO typically varies from $5 \times 10^{-4}$ and $4 \times 10^{-1} \mathrm{~S} / \mathrm{m}[61,62]$ and the conductivity measurement is subject to the specific setup, quality of contacts, sample preparation etc., it would be inaccurate to compare the conductivities between different studies. Rather, it is the conductivity difference between pre and post-treatment materials that matters [29].

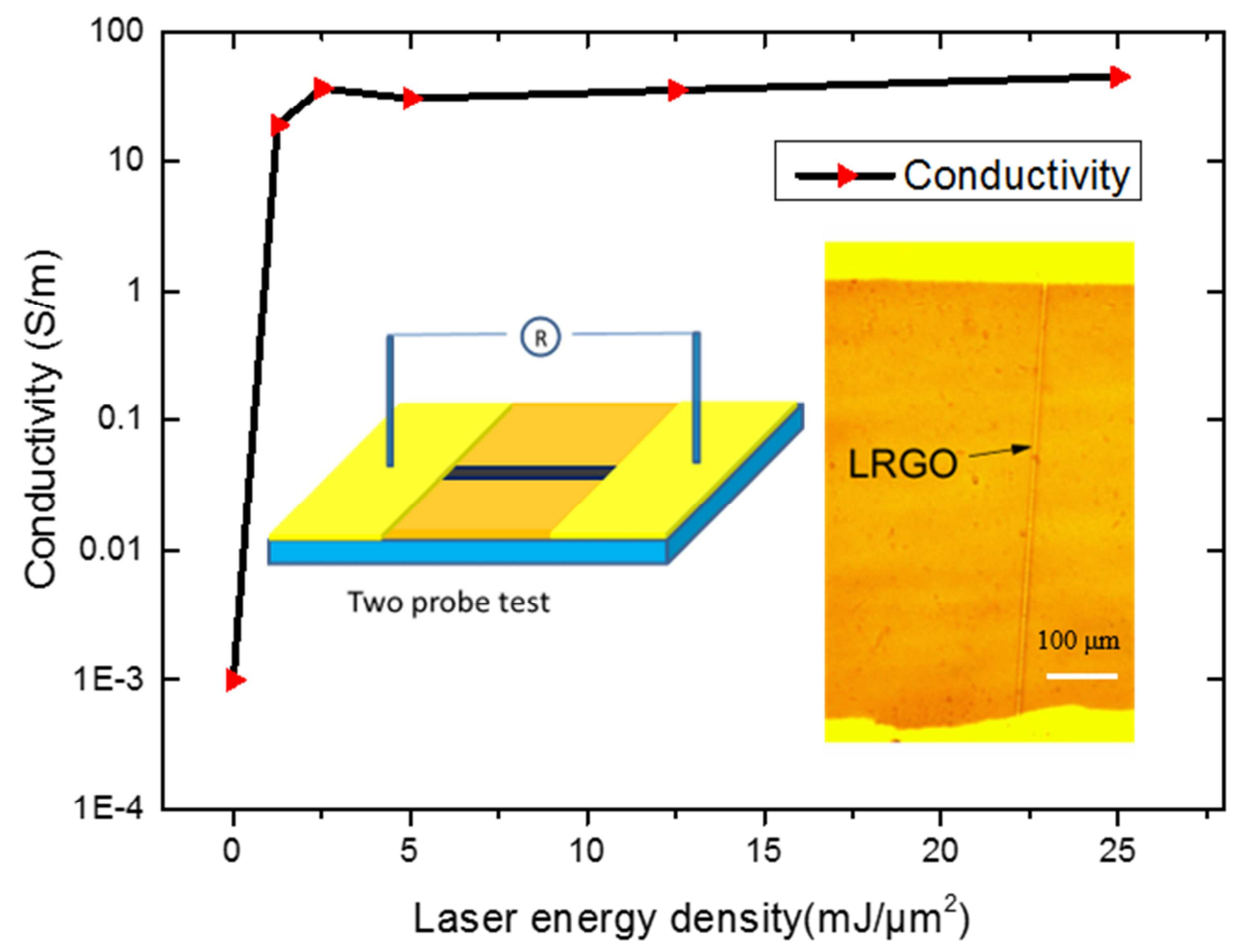

Figure 4 The dependence of the LRGO conductivity on laser energy density. The inset shows the 
schematic figure of conductivity test (left) and microscopic image of a LRGO line between two gold

electrodes for conductivity test, the scale bar is $100 \mu \mathrm{m}$ (right).

\subsection{The mechanism of $f$ s laser reduction}

We further investigated the mechanism of fs laser reduction. Different laser power was used to tune the reduction degree of GO at scanning speed of $5 \mu \mathrm{m} / \mathrm{s}$. The $\mathrm{C} 1 \mathrm{~s}$ spectra of $\mathrm{GO}$ and LRGOs are deconvoluted into several main peaks including: $\mathrm{sp}^{2}$ hybridized carbon $\left(\mathrm{C}-\mathrm{C} \mathrm{sp}^{2}\right.$ $284.5 \mathrm{eV}), \mathrm{sp}^{3}$ hybridized carbon $\left(\mathrm{C}-\mathrm{C} \mathrm{sp}^{3} 285 \mathrm{eV}\right)$, epoxide/hydroxyl (C-O $\left.286.6 \mathrm{eV}\right)$, carbonyl $(\mathrm{C}=\mathrm{O} 287.6 \mathrm{eV})$, and carboxyl $(\mathrm{COOH} 288.6 \mathrm{eV})$. Table $\mathrm{S} 4$ provides the atomic concentration percentage of chemical state components of GO and LRGOs in the XPS spectra. The $\mathrm{CC}$ refers to the sum of $\mathrm{C}-\mathrm{C} \mathrm{sp}{ }^{2}$ and $\mathrm{C}-\mathrm{C} \mathrm{sp}{ }^{3}$, and the $\mathrm{CO}$ is the combination of $\mathrm{C}-\mathrm{O}, \mathrm{C}=\mathrm{O}$ and $\mathrm{COOH}$. The ratio of percentage of $\mathrm{CC}$ bond to $\mathrm{CO}$ bond rises from 1.02 (GO) to 1.76 (LRGO $13 \mathrm{~mW}$ ), which reveals the effective removal of oxygen after laser treatment.

Figure 5(a-b) illustrates the dependence of atomic concentration percentage of chemical components on laser power. Three main stages can be observed with the increase of laser power. At the first stage (laser power $3 \mathrm{~mW}$ ), the restoration of $\mathrm{C}-\mathrm{C} \mathrm{sp}{ }^{3}$ to $\mathrm{C}-\mathrm{C} \mathrm{sp}{ }^{2}$ is obvious with a decrease of $20.99 \%$ in the percentage of $\mathrm{C}-\mathrm{C} \mathrm{sp}{ }^{3}$ and increase of $26.16 \%$ in that of $\mathrm{C}-\mathrm{C} \mathrm{sp}{ }^{2}$. The percentage of $\mathrm{CO}$ decreased $5.17 \%$, which mostly results from the decreased percentage of $\mathrm{C}=\mathrm{O}$. At the second stage (laser power from 5 to $10 \mathrm{~mW}$ ), both the percentage of $\mathrm{CO}$ and the percentage of $\mathrm{C}-\mathrm{C} \mathrm{sp}^{2}$ are relatively stable, compared to those of the first stage. There is no obvious tendency of further oxygen removal with a laser power of $10 \mathrm{~mW}$. In the third stage (laser power $13 \mathrm{~mW}$ ), there is a clear further $8.11 \%$ decrease of the percentage of CO compared to that of the first stage. In the reduction process, two important sub-processes can be concluded: the restoration of $\mathrm{sp}^{3}$ to $\mathrm{sp}^{2}$ and the removal of oxygen, and these two sub-processes can be tuned by adjusting the laser power.

Figure 5(c-f) shows the photoemission spectra of the C1s of GO and LRGOs fabricated with different laser powers and their curve-fits. The XPS spectra of LRGOs fabricated at different 
laser scanning speed with the power of $7.5 \mathrm{~mW}$ are shown in Figure S5. The laser scanning speed also demonstrates the modulation over the reduction of different oxygen components. Table S6 illustrates the percentage of chemical components with different scanning speeds. It can be concluded that the percentage of oxygen functional groups and $\mathrm{CC} / \mathrm{CO}$ ratio can also be adjusted by changing the laser scanning speed.
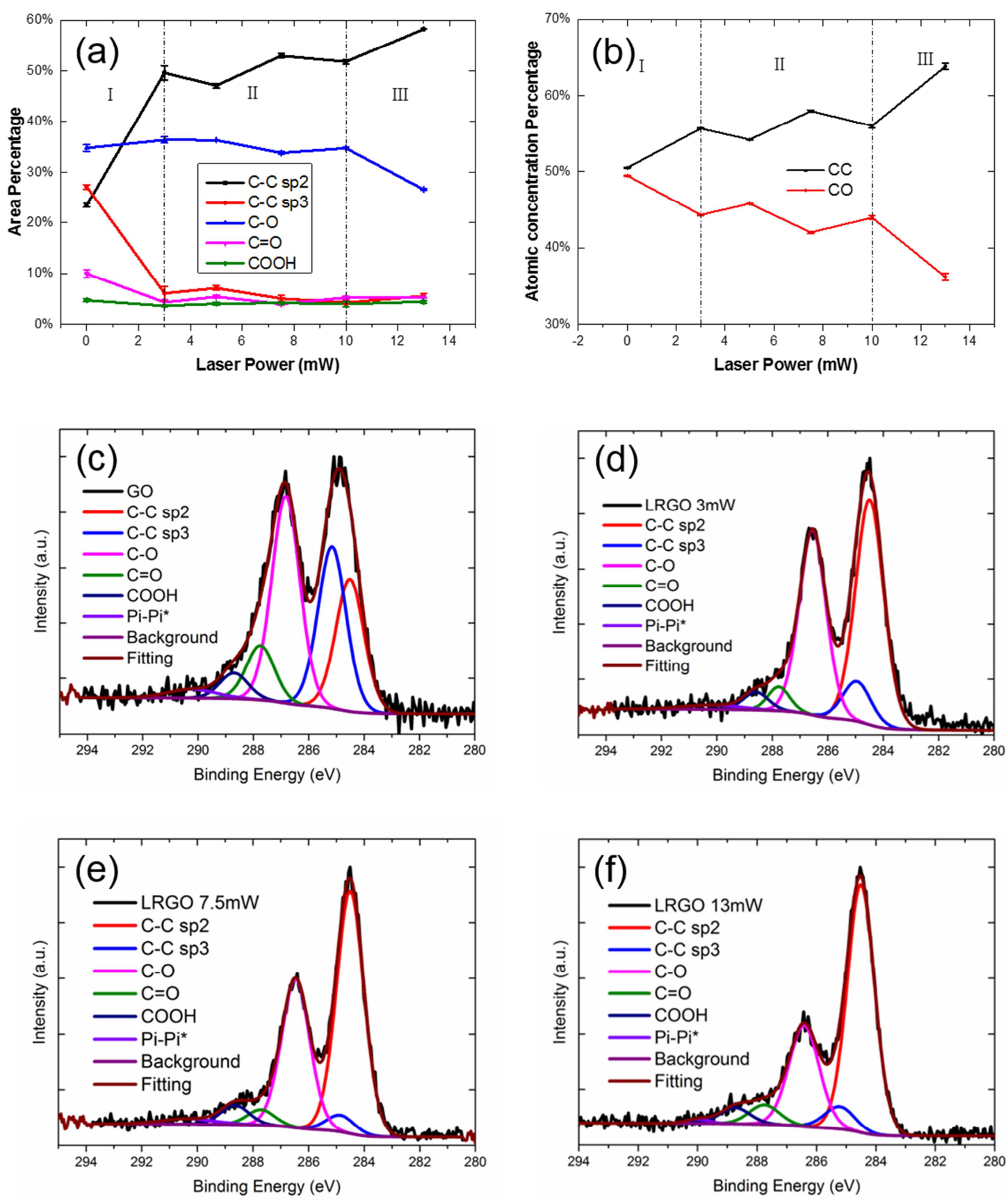

Figure $5(a-b)$ The dependance of atomic concentration percentage of chemical components on laser 
power. (c-f) Peak fitted C1s XPS spectra of (c)GO, and LRGOs fabricated at (d) $3 \mathrm{~mW}$ (e) $7.5 \mathrm{~mW}$ (f) 13

$\mathrm{mW}$.

Figure 6(a) shows the XRD patterns of GO and LRGOs fabricated under different laser powers at scanning speed of $5 \mu \mathrm{m} / \mathrm{s}$, exhibiting a typical peak around $11.92^{\circ}\left(002^{\prime}\right)$. Bragg's equation was applied to evaluate the distance between layers, denoted as D (Figure 6(b) and Table S5). It is found that after the fs laser treatment of GO, the inter-layer distance has expanded from 7.44 (GO) to $7.75 \AA$ (LRGO $13 \mathrm{~mW}$ ), as shown in Figure 6(c). This expansion of interlayer space could result from the rapid thermal evaporation of intercalated materials, such as sulfuric acid [63] and water molecules [64], which indicates the thermal effect of the laser. 

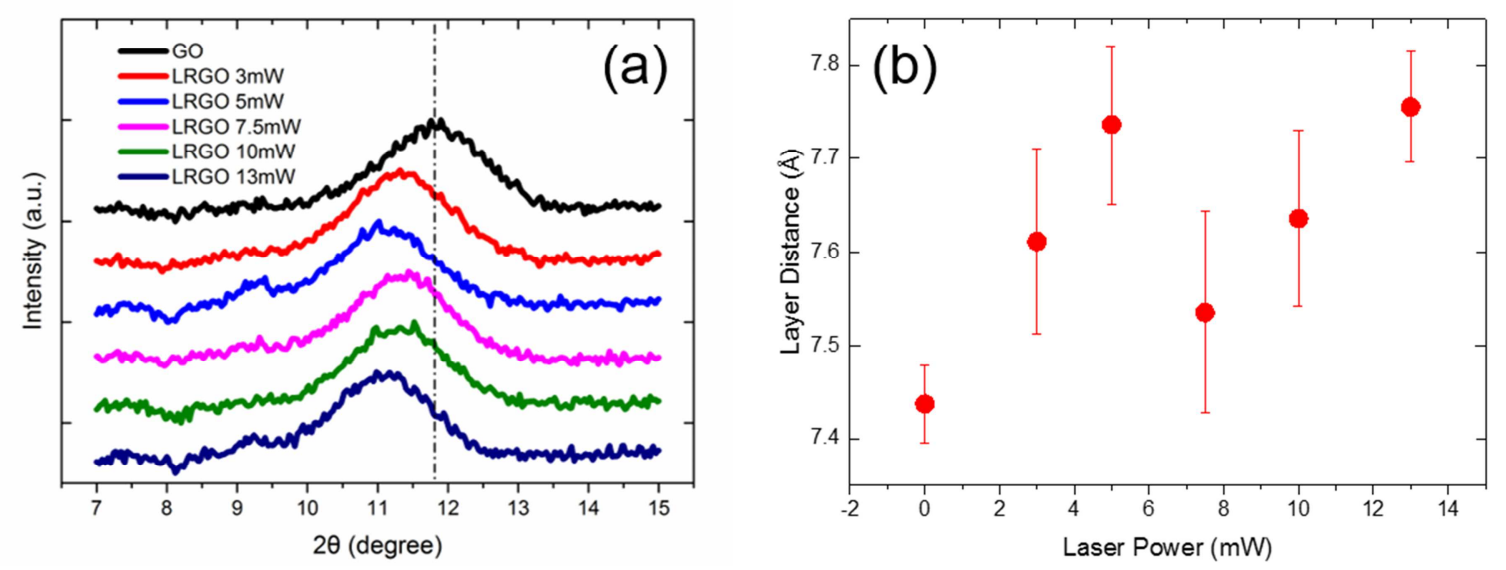

(c)

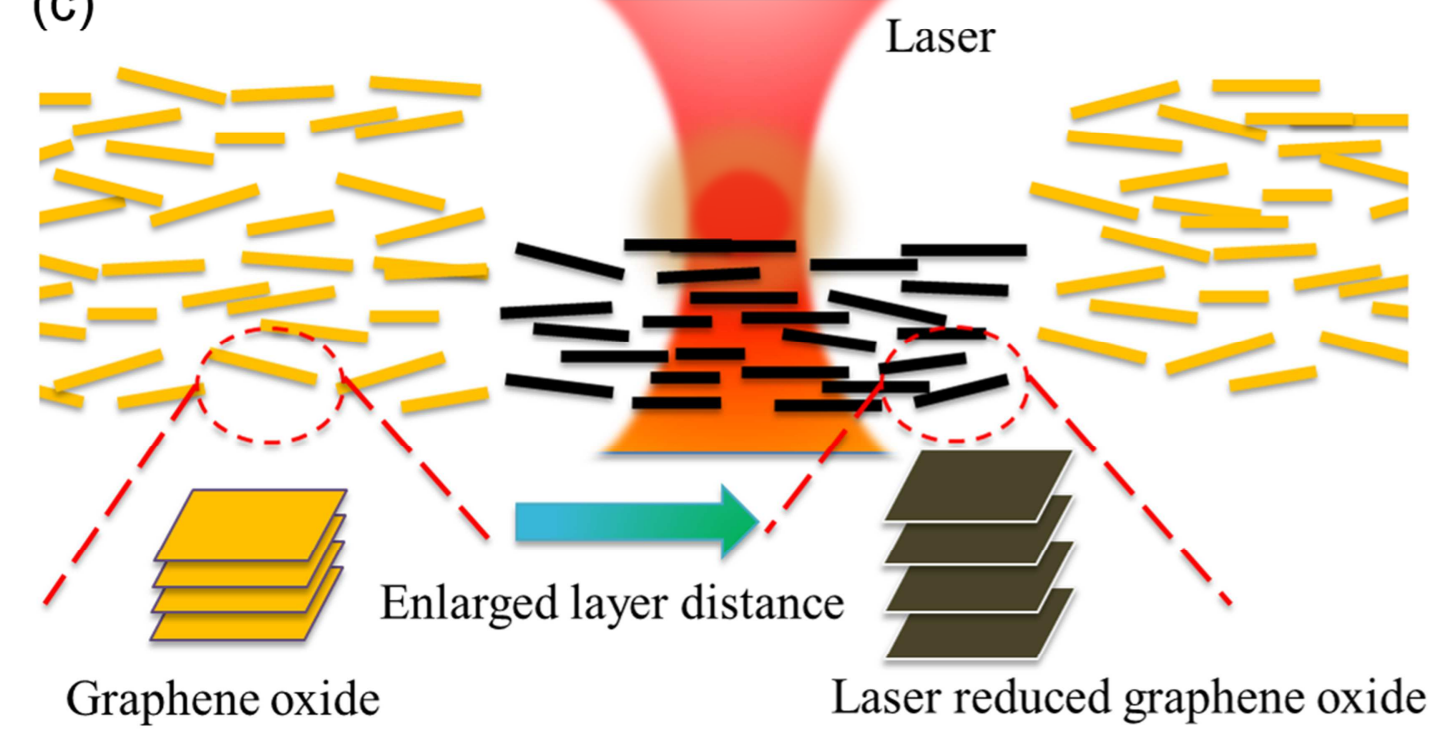

Figure 6 (a) XRD analysis of GO and LRGOs with different laser powers at scanning speed of $5 \mu \mathrm{m} / \mathrm{s}$. (b)

The dependence of layer distance on the power of laser. (c) Schematic illustration of the enlarged layer distance after laser reduction of GO film

\subsubsection{The restoration of $s p^{3}$ to $s p^{2}$}

Figure 7 demonstrates the dependence of the $\mathrm{sp}^{3}$ to $\mathrm{sp}^{2}$ conversion and oxygen removal on the power of laser. The conversion of $\mathrm{sp}^{3}$ carbon into $\mathrm{sp}^{2}$ carbon is very distinctive $(20.99 \%)$ at the laser power of $3 \mathrm{~mW}$ and remains at similar level when the laser power is increased to $13 \mathrm{~mW}$. After irradiation with $3 \mathrm{~mW}$ laser, the ratio of $\mathrm{C}-\mathrm{C} \mathrm{sp}{ }^{2}$ to $\mathrm{C}-\mathrm{C} \mathrm{sp}{ }^{3}$ raises significantly from 0.87 to 8.14 . Before laser treatment, the GO sample had $23.44 \% \mathrm{C}-\mathrm{C} \mathrm{sp}{ }^{2}$ and $27.09 \% \mathrm{C}-\mathrm{C} \mathrm{sp}{ }^{3}$. After 
laser reduction at $3 \mathrm{~mW}$, the percentage of $\mathrm{C}-\mathrm{C} \mathrm{sp}{ }^{3}$ decreased from $27.09 \%$ to $6.09 \%$, while the percentage of $\mathrm{C}-\mathrm{C} \mathrm{sp} \mathrm{sp}^{2}$ increases from $23.44 \%$ to $49.60 \%$. This restoration process reorganized defective structure in GO back to graphene structure. Meanwhile, the percentage of CO (oxygen containing groups) only decreased $5.17 \%$ during this process. Our results show that the restoration of $\mathrm{C}-\mathrm{C} \mathrm{sp}^{3}$ to $\mathrm{C}-\mathrm{C} \mathrm{sp}^{2}$ can occur at relatively low power without having much oxygen removed. Direct conversion of $\mathrm{sp}^{3}$ to $\mathrm{sp}^{2}$ carbon has been reported both experimentally and theoretically [65-67]. The activation energy for this conversion was determined to be $3.5 \pm$ $0.9 \mathrm{eV}$ or $3.3 \mathrm{eV}[65,66]$ and this conversion process can be triggered by thermal or photo treatment $[65,67]$. Table 1 lists the comparison of $\mathrm{sp}^{2} / \mathrm{sp}^{3}$ and $\mathrm{CC} / \mathrm{CO}$ of GO reduced with different methods. This laser reduction methods shows a high $\mathrm{sp}^{2} / \mathrm{sp}^{3}$ of 12.18 .

\subsubsection{The removal of oxygen during reduction}

By increasing the fs laser power to $13 \mathrm{~mW}$, the percentage of CO decreased from $49.47 \%$ (GO) to $36.19 \%$ (LRGO $13 \mathrm{~mW}$ ), indicating a substantial oxygen removal. However, the laser reduction process demonstrates varied degrees of effect on different oxygen-containing groups. There is an obvious decrease of the percentage of $\mathrm{C}=\mathrm{O}$, when the laser power is $3 \mathrm{~mW}$ or above. While the percentage of $\mathrm{C}-\mathrm{O}$ does not decrease substantially until the laser power reaches 13 $\mathrm{mW}$. For the percentage of $\mathrm{COOH}$, there is no distinctive change after applying laser power from 3 to $13 \mathrm{~mW}$.

Our finding revealed that the $780 \mathrm{~nm}$ fs laser reduction exhibits both carbon atom restoration and the removal of oxygen. At a lower laser power $(3 \mathrm{~mW})$, the restoration takes the main effect and there is little oxygen removal during the reduction. At a higher power $(13 \mathrm{~mW})$, further oxygen removal become more obvious. Although the fs laser is considered to be ineffective for generating heat because of its ultra-short duration [68], due to the recombination of electrons and holes, heating is also accompanied with the photochemical process [45]. The fs laser can still produce considerable thermal for GO reduction processes and might also cause the thermal 
ablation and thermal expansion of LRGO interlayers. The temperature under such a laser system's irradiation has been estimated to be $304{ }^{\circ} \mathrm{C}(3 \mathrm{~mW})$ and $340{ }^{\circ} \mathrm{C}(13 \mathrm{~mW})$, employing the model developed by Li et. al [47]. It's been established that the threshold temperature for reducing GO is in the range of $200-230{ }^{\circ} \mathrm{C}[69,70]$ and the higher the temperature above this point the increased reduction extent can be achieved [71]. Therefore, when our laser power varies from $3 \mathrm{~mW}$ to $13 \mathrm{~mW}$, the elevated temperatures can all result in $\mathrm{GO}$ thermal reduction. With increased laser power, the temperature induced by the laser also increases, enhancing the removal of oxygen components. Moreover, considering that the threshold of GO photoreduction is at about $390 \mathrm{~nm}$ [72], two-photon absorption is likely to occur, which induces the photochemical effect that can play an important role in the reduction process. It can be concluded that both the photochemical and photothermal effects induced by the $780 \mathrm{~nm}$ fs laser might coexist in the restoration and oxygen removal processes.

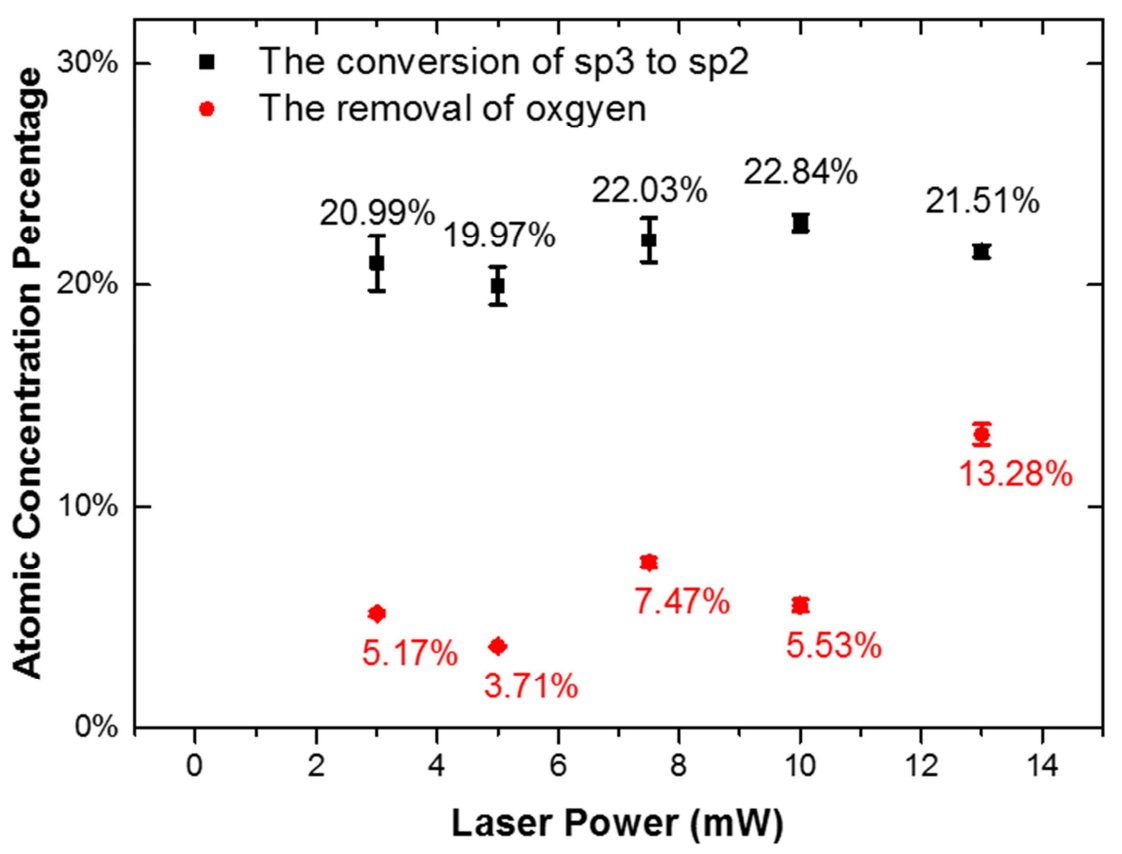


Figure 7 The dependance of the conversion of $\mathrm{sp}^{3}$ to $\mathrm{sp}^{2}$ and the removal of oxygen on laser power.

Table 1 The comparison of components of GO reduced with different methods

\begin{tabular}{llll}
\hline Reduction methods of GO & $\mathbf{s p}^{\mathbf{2}} / \mathbf{s} \mathbf{p}^{\mathbf{3}}$ & $\mathbf{C C} / \mathbf{C O}$ & Refer. \\
\hline Chemical reduction & $1.28-3.29$ & $1.37-2.24$ & {$[73]$} \\
\hline Hydrothermal reduction & $5.58-6.6$ & $3.45-4.16$ & {$[74]$} \\
\hline Thermal reduction & - & 3.44 & {$[75]$} \\
\hline Laser reduction & $6.62-12.18$ & $1.19-1.76$ & this work \\
\hline
\end{tabular}

\section{Conclusions}

In conclusion, we have studied the influence of laser fluence (power) and energy density (power, scanning speed) of a $780 \mathrm{~nm}$ fs laser in reducing the GO film. Our results confirm that there are two sub-processes in the laser reduction process, namely the direct conversion of $\mathrm{sp}^{3}$ carbon into $\mathrm{sp}^{2}$ carbon and the removal of oxygen. Both the photochemical and photothermal effects appear to be involved in the sub-processes of the removal of oxygen and the conversion of $\mathrm{sp}^{3}$ to $\mathrm{sp}^{2}$.

Importantly, we found that the two coexisting sub-processes during the laser reduction can be tuned by adjusting the power and scanning speed of the laser. The conversion of $\mathrm{sp}^{3}$ hybridized carbon into $\mathrm{sp}^{2}$ carbon is very distinctive $(20.99 \%)$ at low laser power of $3 \mathrm{~mW}$ and remains stable at about $21 \%$ with increasing the power of laser to $13 \mathrm{~mW}$. In contrast, the removal of oxygen is limited (about 5\%) until the laser power is raised up to $13 \mathrm{~mW}$. At the power of $13 \mathrm{~mW}$, the removal of oxygen can be enhanced to $13.28 \%$.

We have also found that the amount of the different oxygen-contained groups can be controlled by the power of laser. The percentage of $\mathrm{C}=\mathrm{O}$ decreased obviously from $9.98 \%$ to $4.32 \%$ when the laser power was only $3 \mathrm{~mW}$, but the percentage of $\mathrm{C}-\mathrm{O}$ did not decrease substantially until the laser power reaches $13 \mathrm{~mW}$. It's also noted that the percentage of $\mathrm{COOH}$ (about 4\%) remained almost constant despite the change in laser power in the range of 3 to $13 \mathrm{~mW}$. 
This selective and controllable reduction of GO could be utilized to prepare LRGO with precisely controlled functional groups for specific applications. The C-O groups attached to the basal planes are the main influencing factor on the conductivity of reduced $\mathrm{GO}$ while $\mathrm{C}=\mathrm{O}$ present at the edges have a limited influence. Consequently, by selectively eliminating the C-O groups and preserving the $\mathrm{C}=\mathrm{O}$ groups, the $\mathrm{RGO}$ demonstrates improved electrical conductivity and still be dispersible in solution $[11,76]$. By adjusting laser fluence (power), the content of oxygen containing groups of the LRGO can be decreased from $49.47 \%$ to $36.19 \%$; the $\mathrm{I}_{\mathrm{D}} / \mathrm{I}_{\mathrm{G}}$ ratio of LRGO can be modulated from 1.40 to 1.13; and the decrease of film thickness during the laser induced reduction can be varied from $20 \%$ to $70 \%$ of the original thickness of GO film. The optimum condition for reducing $\mathrm{GO}$ using $\mathrm{I}_{\mathrm{D}} / \mathrm{I}_{\mathrm{G}}$ ratio as the indicator is the fluence of $8.3 \mathrm{~mJ}$ $\mathrm{cm}^{-2}$ and energy density of $65 \mathrm{~mJ} \mu \mathrm{m}^{-2}$ (power $13 \mathrm{~mW}$, scanning speed $0.1 \mu \mathrm{m} / \mathrm{s}$ ) in our laser system. After laser reduction, the conductivity of GO can be improved from $10^{-3} \mathrm{~S} / \mathrm{m}$ to $45.5 \mathrm{~S} / \mathrm{m}$. This research provides solid evidence for the dual sub-processes underlying the laser induced reduction of $\mathrm{GO}$, which is critical for mechanistic understanding as well as the effective modulation of LRGO for real applications. Given the current scale of GO production and its broad applications in energy storage, electronics, and catalysis etc., such a laser-induced direct reduction method can be envisioned as a facile process that can be readily incorporated into in line reduction of GO in a roll-to-roll process. 


\section{Acknowledgements}

This work is supported by Griffith University International Postgraduate Scholarship and a Commonwealth Scientific and Industrial Research Organisation (CSIRO) Top-up Scholarship. The work was partially supported by the ARC DP160104089. B.H. wishes to thank the support of an Australian Government Research Training Program Scholarship. The authors acknowledge the support from the Queensland node of the Australian National Fabrication Facility (ANFF), a company established under the National Collaborative Research Infrastructure Strategy to provide nano-and microfabrication facilities for Australia's researchers. We also thank the technical support from the Queensland Micro- and Nanotechnology Centre at Griffith University, and the Centre for Microscopy and Microanalysis at the University of Queensland.

\section{References}

[1] Geim AK, Novoseloy KS. The rise of graphene. Nat Mater 2007;6(3):183-91.

[2] Novoselov KS, Fal V, Colombo L, Gellert P, Schwab M, Kim K. A roadmap for graphene. Nature 2012;490(7419):192-200.

[3] Li X, Zhu Y, Cai W, Borysiak M, Han B, Chen D, et al. Transfer of large-area graphene films for high-performance transparent conductive electrodes. Nano Lett 2009;9(12):4359-63.

[4] Huang Y, Liang JJ, Chen YS. An Overview of the Applications of Graphene-Based Materials in Supercapacitors. Small 2012;8(12):1805-34.

[5] Liu Y, Dong X, Chen P. Biological and chemical sensors based on graphene materials. Chem Soc Rev 2012;41(6):2283-307.

[6] Huang X, Yin ZY, Wu SX, Qi XY, He QY, Zhang QC, et al. Graphene-Based Materials: Synthesis, Characterization, Properties, and Applications. Small 2011;7(14):1876-902.

[7] Novoselov KS, Geim AK, Morozov SV, Jiang D, Zhang Y, Dubonos SV, et al. Electric field effect in atomically thin carbon films. Science 2004;306(5696):666-9.

[8] Berger C, Song Z, Li X, Wu X, Brown N, Naud C, et al. Electronic confinement and coherence in patterned epitaxial graphene. Science 2006;312(5777):1191-6. 
[9] Bae S, Kim H, Lee Y, Xu X, Park JS, Zheng Y, et al. Roll-to-roll production of 30-inch graphene films for transparent electrodes. Nat Nanotechnol 2010;5(8):574-8.

[10] Kim KS, Zhao Y, Jang H, Lee SY, Kim JM, Kim KS, et al. Large-scale pattern growth of graphene films for stretchable transparent electrodes. Nature 2009;457(7230):706-10.

[11] Pei SF, Cheng HM. The reduction of graphene oxide. Carbon 2012;50(9):3210-28.

[12] Wei Z, Wang D, Kim S, Kim SY, Hu Y, Yakes MK, et al. Nanoscale tunable reduction of graphene oxide for graphene electronics. Science 2010;328(5984):1373-6.

[13] Wang SJ, Geng Y, Zheng QB, Kim JK. Fabrication of highly conducting and transparent graphene films. Carbon 2010;48(6):1815-23.

[14] Voiry D, Yang J, Kupferberg J, Fullon R, Lee C, Jeong HY, et al. High-quality graphene via microwave reduction of solution-exfoliated graphene oxide. Science 2016;353(6306):1413-6.

[15] Alotaibi F, Tung TT, Nine MJ, Kabiri S, Moussa M, Tran DNH, et al. Scanning atmospheric plasma for ultrafast reduction of graphene oxide and fabrication of highly conductive graphene films and patterns. Carbon 2018;127:113-21.

[16] Akhavan O, Abdolahad M, Esfandiar A, Mohatashamifar M. Photodegradation of Graphene Oxide Sheets by TiO2 Nanoparticles after a Photocatalytic Reduction. J Phys Chem C 2010;114(30):12955-9.

[17]Cote LJ, Cruz-Silva R, Huang J. Flash reduction and patterning of graphite oxide and its polymer composite. J Am Chem Soc 2009;131(31):11027-32.

[18]Han DD, Zhang YL, Liu Y, Liu YQ, Jiang HB, Han B, et al. Bioinspired Graphene Actuators Prepared by Unilateral UV Irradiation of Graphene Oxide Papers. Adv Funct Mater 2015;25(28):4548-57.

[19]Han DD, Zhang YL, Jiang HB, Xia H, Feng J, Chen QD, et al. Moisture-responsive graphene paper prepared by self-controlled photoreduction. Adv Mater 2015;27(2):332-8. [20] Sokolov DA, Rouleau CM, Geohegan DB, Orlando TM. Excimer laser reduction and patterning of graphite oxide. Carbon 2013;53:81-9.

[21]Ibrahim KH, Irannejad M, Hajialamdari M, Ramadhan A, Musselman KP, Sanderson J, et al. A Novel Femtosecond Laser-Assisted Method for the Synthesis of Reduced Graphene Oxide Gels and Thin Films with Tunable Properties. Adv Mater Interfaces 2016;3(14):1500864. [22]Jiang HB, Zhang YL, Han DD, Xia H, Feng J, Chen QD, et al. Bioinspired Fabrication of Superhydrophobic Graphene Films by Two-Beam Laser Interference. Adv Funct Mater 2014;24(29):4595-602.

[23]Liu YQ, Zhang YL, Liu Y, Jiang HB, Han DD, Han B, et al. Surface and Interface Engineering of Graphene Oxide Films by Controllable Photoreduction. Chem Rec 2016;16(3):1244-55.

[24]Han DD, Zhang YL, Ma JN, Liu YQ, Han B, Sun HB. Light-Mediated Manufacture and Manipulation of Actuators. Adv Mater 2016;28(38):8328-43.

[25] Wang S, Ouyang X, Feng Z, Cao Y, Gu M, Li X. Diffractive photonic applications mediated by laser reduced graphene oxides. Opto-Electronic Advances 2018;1(2):170002.

[26] Singh RK, Kumar R, Singh DP. Graphene oxide: strategies for synthesis, reduction and frontier applications. RSC Adv 2016;6(69):64993-5011.

[27]Zhou Y, Bao Q, Varghese B, Tang LAL, Tan CK, Sow CH, et al. Microstructuring of graphene oxide nanosheets using direct laser writing. Adv Mater 2010;22(1):67-71. 
[28]Li X, Ren H, Chen X, Liu J, Li Q, Li C, et al. Athermally photoreduced graphene oxides for three-dimensional holographic images. Nat Commun 2015;6:6984.

[29] Wan Z, Streed EW, Lobino M, Wang S, Sang RT, Cole IS, et al. Laser-Reduced Graphene: Synthesis, Properties, and Applications. Adv Mater Technol 2018:1700315.

[30]Gao W, Singh N, Song L, Liu Z, Reddy AL, Ci L, et al. Direct laser writing of micro-supercapacitors on hydrated graphite oxide films. Nat Nanotechnol 2011;6(8):496-500. [31] Wen F, Hao C, Xiang J, Wang L, Hou H, Su Z, et al. Enhanced laser scribed flexible graphene-based micro-supercapacitor performance with reduction of carbon nanotubes diameter. Carbon 2014;75:236-43.

[32] Ghoniem E, Mori S, Abdel-Moniem A. Low-cost flexible supercapacitors based on laser reduced graphene oxide supported on polyethylene terephthalate substrate. J Power Sources 2016;324:272-81.

[33] Guo L, Jiang HB, Shao RQ, Zhang YL, Xie SY, Wang JN, et al. Two-beam-laser interference mediated reduction, patterning and nanostructuring of graphene oxide for the production of a flexible humidity sensing device. Carbon 2012;50(4):1667-73.

[34] Strong V, Dubin S, El-Kady MF, Lech A, Wang Y, Weiller BH, et al. Patterning and electronic tuning of laser scribed graphene for flexible all-carbon devices. ACS Nano 2012;6(2):1395-403.

[35] Tian H, Shu Y, Wang XF, Mohammad MA, Bie Z, Xie QY, et al. A graphene-based resistive pressure sensor with record-high sensitivity in a wide pressure range. Sci Rep 2015;5:8603.

[36] He Y, Zhu L, Liu Y, Ma JN, Han DD, Jiang HB, et al. Femtosecond Laser Direct Writing of Flexible All-Reduced Graphene Oxide FET. IEEE Photonic Technol Lett 2016;28(18):1996-9.

[37]Petridis C, Lin YH, Savva K, Eda G, Kymakis E, Anthopoulos TD, et al. Post-fabrication, in situ laser reduction of graphene oxide devices. Appl Phys Lett 2013;102(9):093115.

[38]Chen HY, Han DD, Tian Y, Shao RQ, Wei S. Mask-free and programmable patterning of graphene by ultrafast laser direct writing. Chem Phys 2014;430:13-7.

[39] Thekkekara LV, Jia B, Zhang Y, Qiu L, Li D, Gu M. On-chip energy storage integrated with solar cells using a laser scribed graphene oxide film. Appl Phys Lett 2015;107(3):031105.

[40] Arul R, Oosterbeek RN, Robertson J, Xu G, Jin J, Simpson MC. The mechanism of direct laser writing of graphene features into graphene oxide films involves photoreduction and thermally assisted structural rearrangement. Carbon 2016;99:423-31.

[41] Guan YC, Fang YW, Lim GC, Zheng HY, Hong MH. Fabrication of Laser-reduced Graphene Oxide in Liquid Nitrogen Environment. Sci Rep 2016;6:28913.

[42]Bobrinetskiy II, Emelianov AV, Smagulova SA, Komarov IA, Otero N, Romero PM. Laser direct 3D patterning and reduction of graphene oxide film on polymer substrate. Mater Lett 2017; 187:20-3.

[43]El-Kady MF, Kaner RB. Scalable fabrication of high-power graphene micro-supercapacitors for flexible and on-chip energy storage. Nat Commun 2013;4:1475.

[44]Lin J, Peng Z, Liu Y, Ruiz-Zepeda F, Ye R, Samuel EL, et al. Laser-induced porous graphene films from commercial polymers. Nat Commun 2014;5:5714.

[45]Guo L, Shao RQ, Zhang YL, Jiang HB, Li XB, Xie SY, et al. Bandgap Tailoring and Synchronous Microdevices Patterning of Graphene Oxides. J Phys Chem C 2012;116(5):3594-9. [46]Bradder P, Ling SK, Wang S, Liu S. Dye adsorption on layered graphite oxide. J Chem Eng 
Data 2010;56(1):138-41.

[47]Li X, Zhang Q, Chen X, Gu M. Giant refractive-index modulation by two-photon reduction of fluorescent graphene oxides for multimode optical recording. Sci Rep 2013;3:2819. [48]Li RZ, Peng R, Kihm KD, Bai S, Bridges D, Tumuluri U, et al. High-rate in-plane micro-supercapacitors scribed onto photo paper using in situ femtolaser-reduced graphene oxide/Au nanoparticle microelectrodes. Energy Environ Sci 2016;9(4):1458-67.

[49]Longo A, Verucchi R, Aversa L, Tatti R, Ambrosio A, Orabona E, et al. Graphene oxide prepared by graphene nanoplatelets and reduced by laser treatment. Nanotechnology 2017;28(22):224002.

[50]Zhang YL, Guo L, Wei S, He YY, Xia H, Chen QD, et al. Direct imprinting of microcircuits on graphene oxides film by femtosecond laser reduction. Nano Today 2010;5(1):15-20.

[51]Zerda TW, Xu W, Yang H, Gerspacher M. The effects of heating and cooling rates on the structure of carbon black particles. Rubber Chem Technol 1998;71(1):26-37.

[52]Hawaldar R, Merino P, Correia MR, Bdikin I, Gracio J, Mendez J, et al. Large-area high-throughput synthesis of monolayer graphene sheet by Hot Filament Thermal Chemical Vapor Deposition. Sci Rep 2012;2.

[53]Huang L, Liu Y, Ji LC, Xie YQ, Wang T, Shi WZ. Pulsed laser assisted reduction of graphene oxide. Carbon 2011;49(7):2431-6.

[54]Cançado LG, Takai K, Enoki T, Endo M, Kim YA, Mizusaki H, et al. General equation for the determination of the crystallite size La of nanographite by Raman spectroscopy. Appl Phys Lett 2006;88(16):163106.

[55]Ferrari AC, Meyer JC, Scardaci V, Casiraghi C, Lazzeri M, Mauri F, et al. Raman Spectrum of Graphene and Graphene Layers. Phys Rev Lett 2006;97(18):187401.

[56]Han DD, Zhang YL, Ma JN, Liu Y, Mao JW, Han CH, et al. Sunlight-Reduced Graphene Oxides as Sensitive Moisture Sensors for Smart Device Design. Adv Mater Technol 2017;2(8):1700045.

[57] Tao Y, Varghese B, Jaiswal M, Wang S, Zhang Z, Oezyilmaz B, et al. Localized insulator-conductor transformation of graphene oxide thin films via focused laser beam irradiation. Appl Phys A 2012;106(3):523-31.

[58] Mukherjee R, Thomas AV, Krishnamurthy A, Koratkar N. Photothermally reduced graphene as high-power anodes for lithium-ion batteries. ACS Nano 2012;6(9):7867-78.

[59] Ghadim EE, Rashidi N, Kimiagar S, Akhavan O, Manouchehri F, Ghaderi E. Pulsed laser irradiation for environment friendly reduction of graphene oxide suspensions. Appl Surf Sci 2014;301:183-8.

[60] Jo G, Choe M, Lee S, Park W, Kahng YH, Lee T. The application of graphene as electrodes in electrical and optical devices. Nanotechnology 2012;23(11):112001.

[61]Park S, An J, Piner RD, Jung I, Yang D, Velamakanni A, et al. Aqueous suspension and characterization of chemically modified graphene sheets. Chem Mater 2008;20(21):6592.

[62] Gilje S, Han S, Wang M, Wang KL, Kaner RB. A chemical route to graphene for device applications. Nano Lett 2007;7(11):3394-8.

[63] Hong Y, Wang Z, Jin X. Sulfuric acid intercalated graphite oxide for graphene preparation.

Sci Rep 2013;3:3439.

[64] Stankovich S, Dikin DA, Piner RD, Kohlhaas KA, Kleinhammes A, Jia Y, et al. Synthesis of 
graphene-based nanosheets via chemical reduction of exfoliated graphite oxide. Carbon 2007;45(7):1558-65.

[65]Grierson DS, Sumant AV, Konicek AR, Friedmann TA, Sullivan JP, Carpick RW. Thermal stability and rehybridization of carbon bonding in tetrahedral amorphous carbon. J Appl Phys 2010;107(3):033523.

[66]Ferrari AC, Rodil SE, Robertson J, Milne WI. Is stress necessary to stabilise sp3 bonding in diamond-like carbon? Diamond Relat Mater 2002;11(3):994-9.

[67] Gaudin J, Medvedev N, Chalupský J, Burian T, Dastjani-Farahani S, Hájková V, et al. Photon energy dependence of graphitization threshold for diamond irradiated with an intense XUV FEL pulse. Phys Rev B 2013;88(6):060101.

[68] Sugioka K, Cheng Y. Ultrafast lasers--reliable tools for advanced materials processing. Light Sci Appl 2014;3(4):e149.

[69]Lerf A, He HY, Forster M, Klinowski J. Structure of graphite oxide revisited. J Phys Chem B 1998;102(23):4477-82.

[70]Wang G, Yang Z, Li X, Li C. Synthesis of poly (aniline-co-o-anisidine)-intercalated graphite oxide composite by delamination/reassembling method. Carbon 2005;43(12):2564-70.

[71] Song L, Khoerunnisa F, Gao W, Dou W, Hayashi T, Kaneko K, et al. Effect of high-temperature thermal treatment on the structure and adsorption properties of reduced graphene oxide. Carbon 2013;52:608-12.

[72] Smirnov VA, Arbuzov A, Shul'ga YM, Baskakov S, Martynenko V, Muradyan V, et al. Photoreduction of graphite oxide. High Energy Chem 2011;45(1):57-61.

[73]Velasco-Soto MA, Pérez-García SA, Alvarez-Quintana J, Cao Y, Nyborg L, Licea-Jiménez L. Selective band gap manipulation of graphene oxide by its reduction with mild reagents. Carbon 2015;93:967-73.

[74]Díez N, Śliwak A, Gryglewicz S, Grzyb B, Gryglewicz G. Enhanced reduction of graphene oxide by high-pressure hydrothermal treatment. RSC Adv 2015;5(100):81831-7.

[75]Teng C-C, Ma C-CM, Lu C-H, Yang S-Y, Lee S-H, Hsiao M-C, et al. Thermal conductivity and structure of non-covalent functionalized graphene/epoxy composites. Carbon 2011;49(15):5107-16.

[76] Wasalathilake KC, Galpaya DGD, Ayoko GA, Yan C. Understanding the structure-property relationships in hydrothermally reduced graphene oxide hydrogels. Carbon 2018;137:282-90.

\section{Supplementary information}

Table S1 the parameters of the laser used in the experiment

Center Wavelength $780 \mathrm{~nm}$




$\begin{array}{lc}\text { Pulse width } & 70 \mathrm{fs} \\ \text { Repetition rate } & 50 \mathrm{MHz} \\ \text { Max. laser power } & 13 \mathrm{~mW} \\ \text { Laser spot } & 2 \mu \mathrm{m}\end{array}$

Table S2 the crystal length versus laser power and laser scanning speed

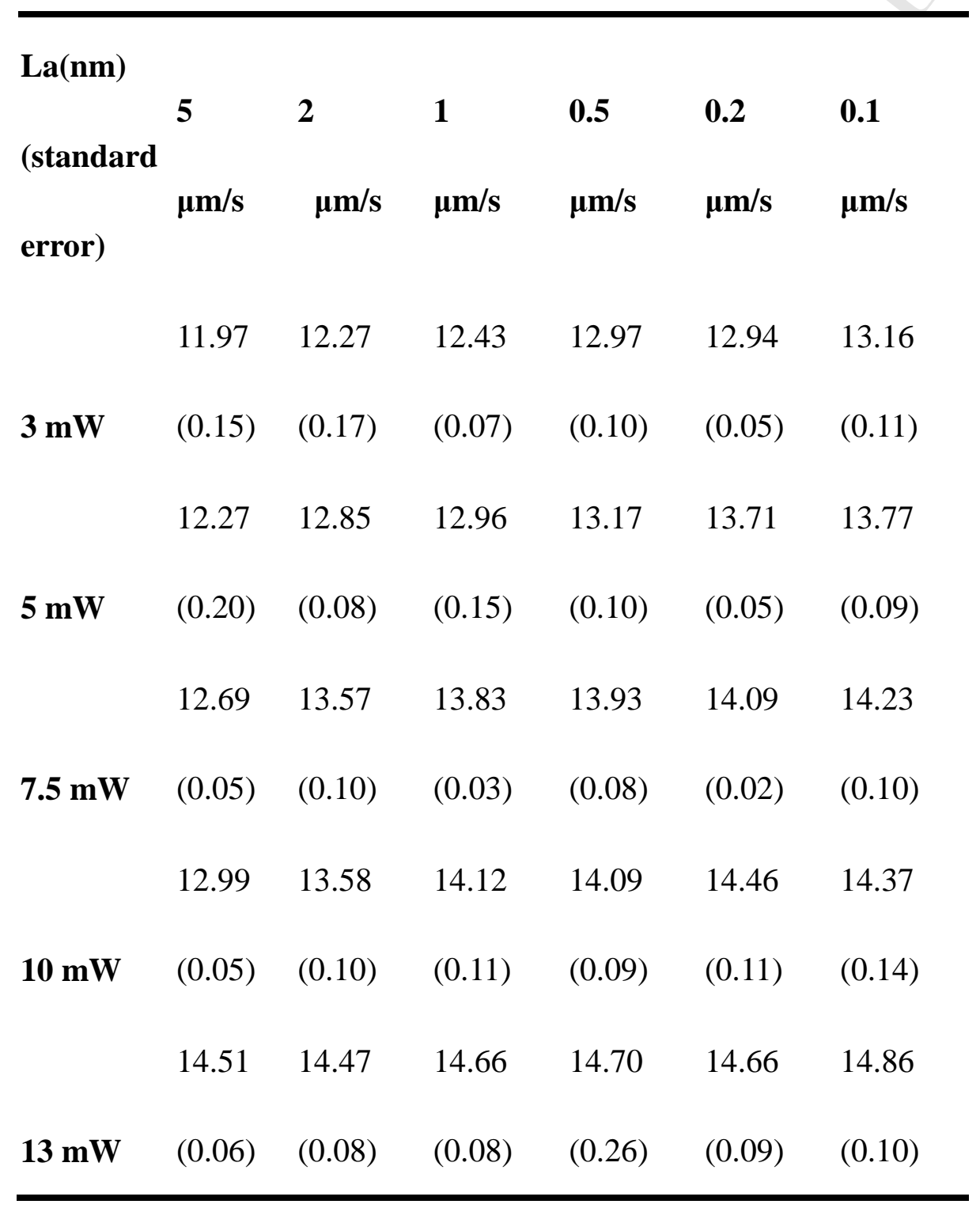


Table $S 3$ the Raman $I_{D} / I_{G}$ ratio of LRGO versus laser power and laser scanning speed

$$
\mathbf{I}_{\mathbf{D}} / \mathbf{I}_{\mathbf{G}}
$$

$\begin{array}{llllll}5 & 2 & 1 & 0.5 & 0.2 & 0.1\end{array}$

(standard error)

$\mu \mathrm{m} / \mathrm{s} \quad \mu \mathrm{m} / \mathrm{s} \quad \mu \mathrm{m} / \mathrm{s} \quad \mu \mathrm{m} / \mathrm{s} \quad \mu \mathrm{m} / \mathrm{s} \quad \mu \mathrm{m} / \mathrm{s}$

$\begin{array}{llllll}1.40 & 1.37 & 1.35 & 1.30 & 1.29 & 1.28\end{array}$

$3 \mathbf{~ m W} \quad(0.018)(0.02) \quad(0.008)(0.005) \quad(0.009)(0.01)$

$$
\begin{array}{llllll}
1.37 & 1.30 & 1.29 & 1.27 & 1.22 & 1.22
\end{array}
$$

$5 \mathbf{~ m W} \quad(0.022)(0.008) \quad(0.014)(0.01) \quad(0.005)(0.008)$
$1.32 \quad 1.23$
1.21
1.20
1.19
1.18

$7.5 \mathrm{~mW} \quad(0.005)(0.009)$

(0.003) (0.007) (0.002) (0.008)
$1.29 \quad 1.23$
1.19
1.19
1.16
1.17

$10 \mathbf{~ m W} \quad(0.005)(0.009) \quad(0.009)(0.008)(0.008)(0.011)$
1.15
1.16
1.15
1.14
1.15
1.13

$13 \mathbf{~ m W} \quad(0.005)(0.006) \quad(0.007)(0.022)(0.007) \quad(0.009)$

\begin{tabular}{|c|c|c|c|c|c|c|c|c|}
\hline \multirow[t]{2}{*}{ Sample } & $\mathrm{C}-\mathrm{C} \mathrm{sp}^{2}$ & $\mathrm{C}-\mathrm{C} \mathrm{sp}^{3}$ & C-O & $\mathrm{C}=\mathrm{O}$ & $\mathrm{COOH}$ & $\mathrm{CC}$ & $\mathrm{CO}$ & $\mathrm{CC} / \mathrm{CO}$ \\
\hline & $284.5 \mathrm{eV}$ & $\begin{array}{c}285 \mathrm{Ev} \\
( \pm 0.2)\end{array}$ & $\begin{array}{c}286.6 \mathrm{eV} \\
( \pm 0.2)\end{array}$ & $\begin{array}{c}287.6 \mathrm{eV} \\
( \pm 0.2)\end{array}$ & $\begin{array}{c}288.6 \mathrm{eV} \\
( \pm 0.2)\end{array}$ & $\begin{array}{c}\mathbf{C}-\mathbf{C} \\
\mathbf{s p}^{2}+ \\
\mathbf{C}-\mathbf{C} \mathbf{s p}^{3}\end{array}$ & $\begin{array}{c}\mathrm{C}-\mathrm{O}+\mathrm{C} \\
=\mathrm{O}+\mathrm{CO} \\
\mathrm{OH}\end{array}$ & \\
\hline GO & $23.44 \%$ & $27.09 \%$ & $34.78 \%$ & $9.98 \%$ & $4.72 \%$ & $50.53 \%$ & $49.47 \%$ & 1.02 \\
\hline $\begin{array}{c}\text { LRGO-3 } \\
\text { mW }\end{array}$ & $49.60 \%$ & $6.09 \%$ & $36.38 \%$ & $4.32 \%$ & $3.61 \%$ & $55.69 \%$ & $44.31 \%$ & 1.26 \\
\hline $\begin{array}{c}\text { LRGO-5 } \\
\text { mW }\end{array}$ & $47.12 \%$ & $7.12 \%$ & $36.32 \%$ & $5.40 \%$ & $4.04 \%$ & $54.24 \%$ & $45.76 \%$ & 1.19 \\
\hline
\end{tabular}

Table S4 XPS chemical state components of GO and LRGOs with different laser power 


\begin{tabular}{ccccccccc}
\hline $\begin{array}{c}\text { LRGO-7 } \\
\mathbf{5} \mathbf{~ m W}\end{array}$ & $52.94 \%$ & $5.06 \%$ & $33.80 \%$ & $4.00 \%$ & $4.20 \%$ & $58.00 \%$ & $42.00 \%$ & 1.38 \\
\hline $\begin{array}{c}\text { LRGO-1 } \\
\mathbf{0 ~} \mathbf{~ m W}\end{array}$ & $51.80 \%$ & $4.25 \%$ & $34.73 \%$ & $5.25 \%$ & $3.96 \%$ & $56.05 \%$ & $43.95 \%$ & 1.28 \\
\hline $\begin{array}{c}\text { LRGO-1 } \\
\mathbf{3} \mathbf{~ m W}\end{array}$ & $58.23 \%$ & $5.57 \%$ & $26.57 \%$ & $5.18 \%$ & $4.45 \%$ & $63.81 \%$ & $36.19 \%$ & 1.76 \\
\hline
\end{tabular}

Table S5 layer distance and crystalline size based on XRD

\begin{tabular}{ccc}
\hline & $\left(\mathbf{O O O 2}^{\prime}\right)$ & \\
\cline { 2 - 3 } Sample & Position & Layer distance \\
& $(\mathbf{2 \theta})$ & $(\mathbf{A})$ \\
\hline GO & 11.92 & 7.43 \\
\hline LRGO-3 $\mathbf{~ m W}$ & 11.4 & 7.77 \\
\hline LRGO-5 $\mathbf{~ m W}$ & 11.25 & 7.87 \\
\hline LRGO-7.5 $\mathbf{~ m W}$ & 11.49 & 7.71 \\
\hline LRGO-10 $\mathbf{~ m W}$ & 11.35 & 7.81 \\
\hline LRGO-13 $\mathbf{~ m W}$ & 11.23 & 7.89 \\
\hline
\end{tabular}

Table S6 XPS chemical state components of GO and LRGOs with different scan speed

\begin{tabular}{|c|c|c|c|c|c|c|c|c|c|}
\hline Sample & C-C sp ${ }^{2}$ & $C-C s p^{3}$ & C-O & $\mathrm{C}=\mathrm{O}$ & $\mathrm{COOH}$ & Pi-Pi* & $\mathrm{CC}$ & $\mathrm{CO}$ & $\mathrm{CC} / \mathrm{CO}$ \\
\hline & $284.5 \mathrm{eV}$ & $\begin{array}{c}285 \mathrm{Ev} \\
( \pm 0.2)\end{array}$ & $\begin{array}{c}286.6 \\
\mathrm{eV} \\
( \pm 0.2)\end{array}$ & $\begin{array}{c}287.6 \\
\mathrm{eV} \\
( \pm 0.2)\end{array}$ & $\begin{array}{c}288.6 \\
\mathrm{eV} \\
( \pm 0.2)\end{array}$ & $\begin{array}{c}290.2 \\
\mathrm{eV} \\
( \pm 0.2)\end{array}$ & 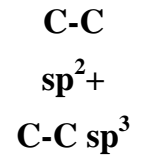 & $\begin{array}{c}\mathrm{C}-\mathrm{O}+\mathrm{C}= \\
\mathrm{O}+\mathrm{COO} \\
\mathrm{H}\end{array}$ & \\
\hline $\begin{array}{c}\text { LRGO-7.5 } \\
\mathrm{mW} \\
5 \mathrm{um} / \mathrm{s}\end{array}$ & $52.61 \%$ & $3.71 \%$ & $33.45 \%$ & $3.43 \%$ & $4.41 \%$ & $2.39 \%$ & $56.32 \%$ & $41.29 \%$ & 1.36 \\
\hline $\begin{array}{c}\text { LRGO-7.5 } \\
\text { mW } \\
2 \mathrm{um} / \mathrm{s}\end{array}$ & $57.07 \%$ & $4.12 \%$ & $28.92 \%$ & $2.75 \%$ & $4.81 \%$ & $2.33 \%$ & $61.19 \%$ & $36.48 \%$ & 1.68 \\
\hline LRGO-7.5 & $54.13 \%$ & $8.78 \%$ & $25.14 \%$ & $5.13 \%$ & $4.58 \%$ & $2.24 \%$ & $62.91 \%$ & $34.85 \%$ & 1.81 \\
\hline
\end{tabular}


mW

$1 \mathrm{um} / \mathrm{s}$

\section{Laser reduction}

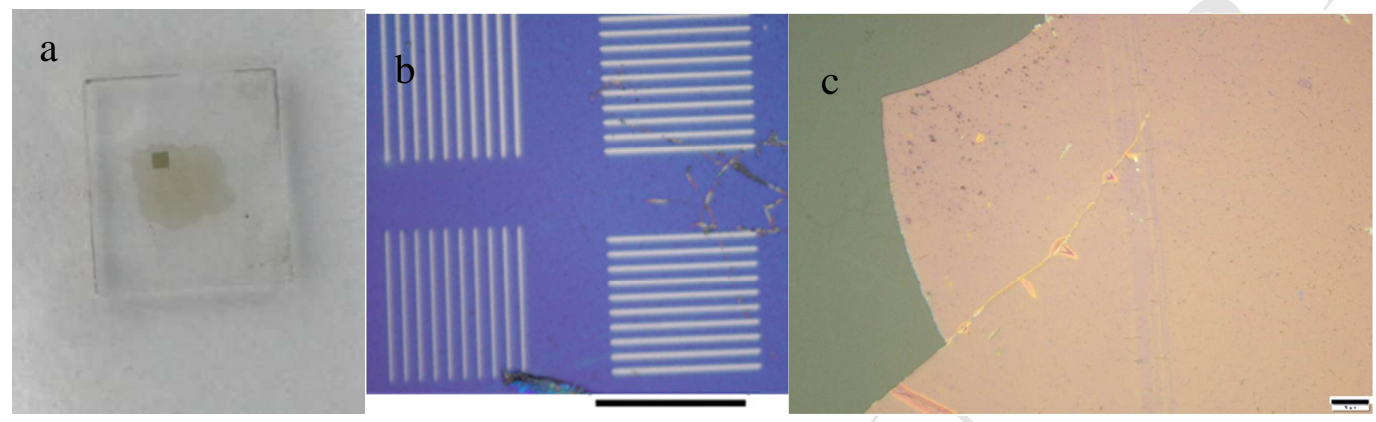

Figure S1 (a) The image of GO film (yellow color) with LRGO (black area, $1 \mathrm{~mm} \times 1 \mathrm{~mm}$ ). (b) The laser patterned figures on GO film, lines array, the scale bar is $100 \mu \mathrm{m}$. $\quad$ (c) The GO sample for thickness measurement under the microscopic (the scale bar is $20 \mu \mathrm{m}$ ).

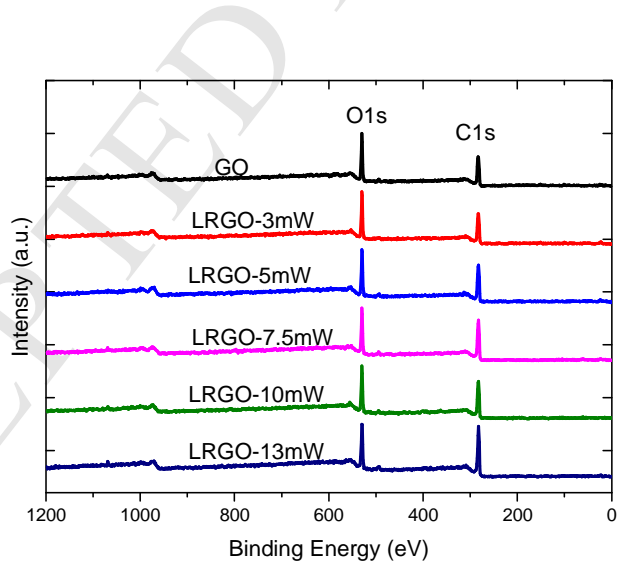

Figure S2 Survey X-ray photoelectron spectra of GO and LRGOs fabricated with laser power of $3 \mathrm{~mW}, 5$ $\mathrm{mW}, 7.5 \mathrm{~mW}, 10 \mathrm{~mW}$ and $13 \mathrm{~mW}$ at laser scanning speed of $5 \mu \mathrm{m} / \mathrm{s}$. 

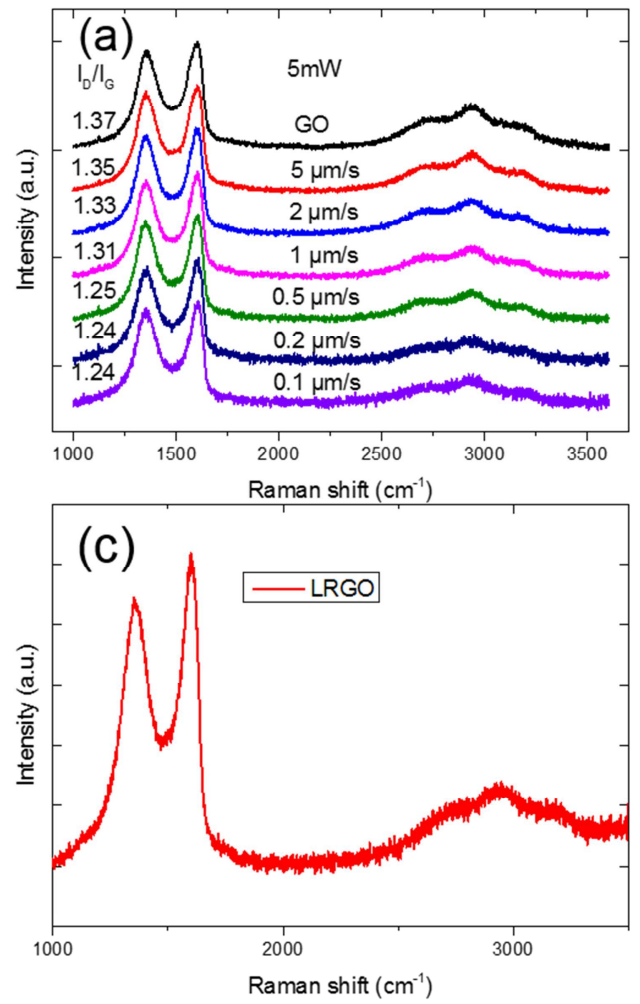
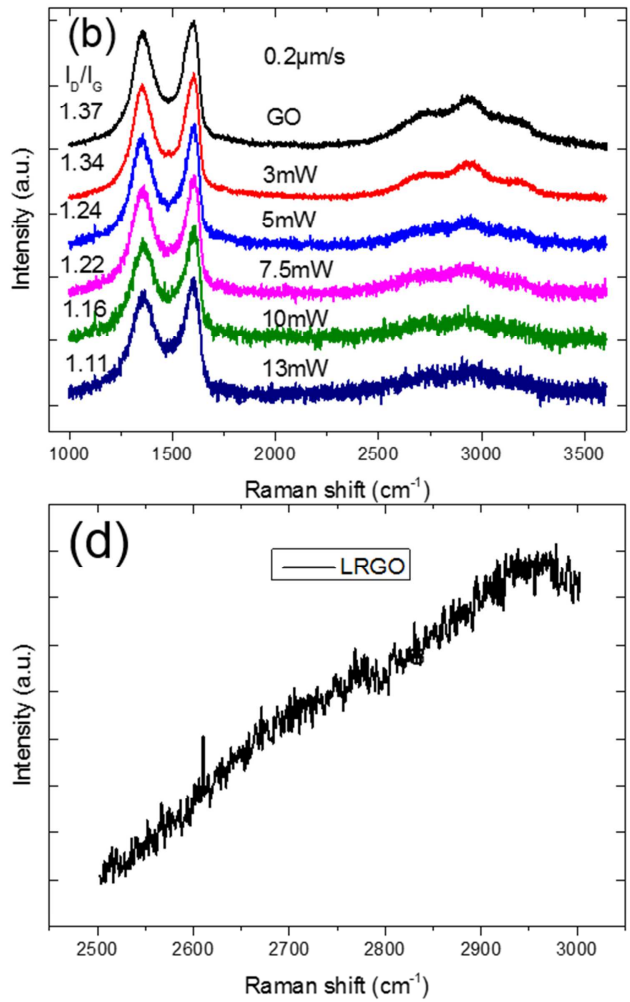

Figure S3 (a) The Raman spectra of GO and LRGOs fabricated at laser scanning speed from $0.1 \mu \mathrm{m} / \mathrm{s}$ to $5 \mu \mathrm{m} / \mathrm{s}$ with constant laser power of $5 \mathrm{~mW}$ (1 accumulation). (b) The Raman spectra of GO and LRGOs fabricated at constant laser scanning speed of $0.2 \mu \mathrm{m} / \mathrm{s}$ with laser power from $3 \mathrm{~mW}$ to $13 \mathrm{~mW}$ (1 accumulation). (c) Raman spectrum of LRGO (13mW, $0.2 \mu \mathrm{m} / \mathrm{s}, 10$ accumulations). (d) Raman spectrum of LRGO (13mW, $0.2 \mu \mathrm{m} / \mathrm{s}, 30$ accumulations). 


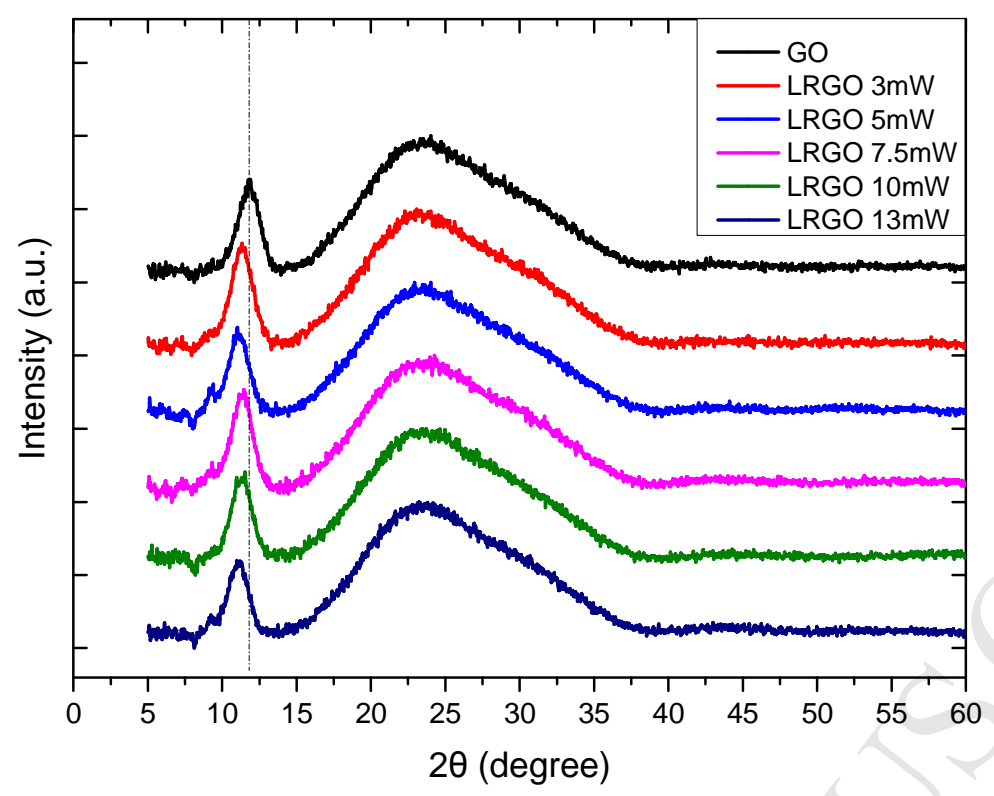

Figure S4 XRD analysis of GO and LRGOs at different laser power with scaning speed $5 \mu \mathrm{m} / \mathrm{s}$.
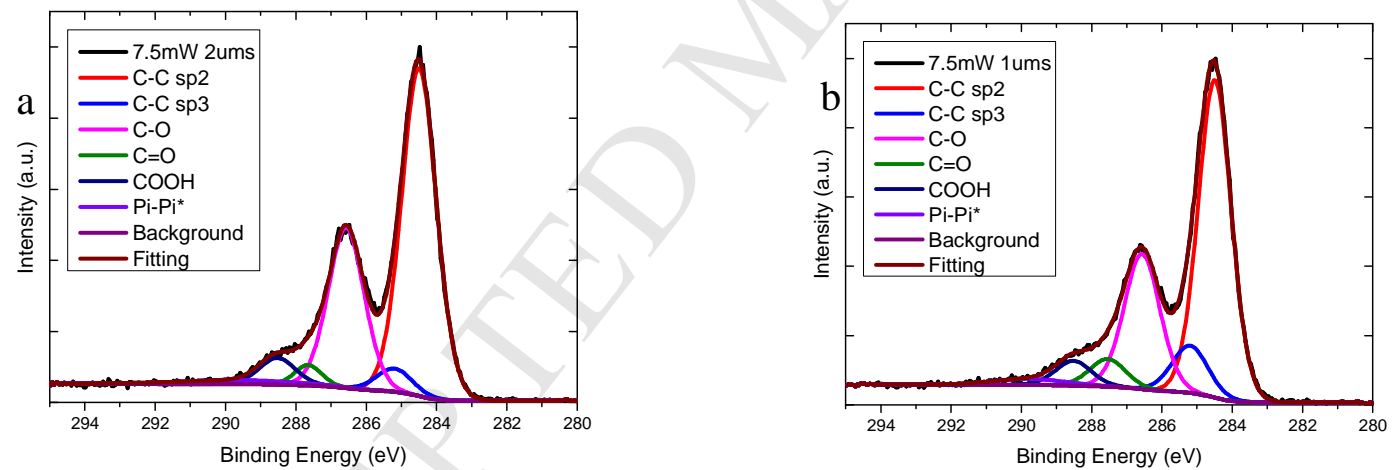

Figure S5 Peak fitted C1s XPS spectra of LRGOs fabricated at laser power of $7.5 \mathrm{~mW}$ with different scan speed (a) $2 \mu \mathrm{m} / \mathrm{s}$ (b) $1 \mu \mathrm{m} / \mathrm{s}$. 


\section{Conductivity test}

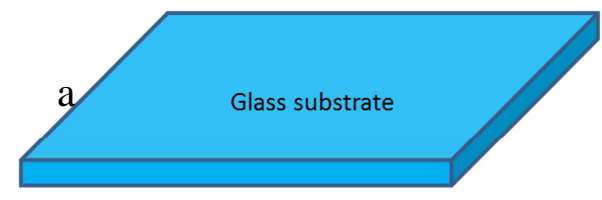

1. GO spin coating
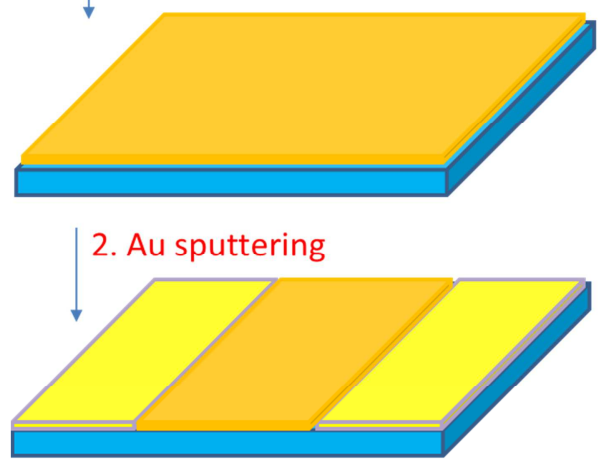

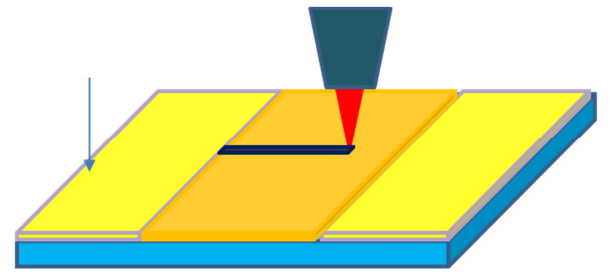

3. Laser reduce graphene oxide

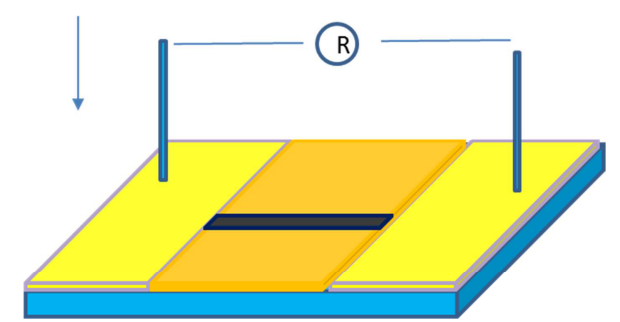

4. Two probe test

b

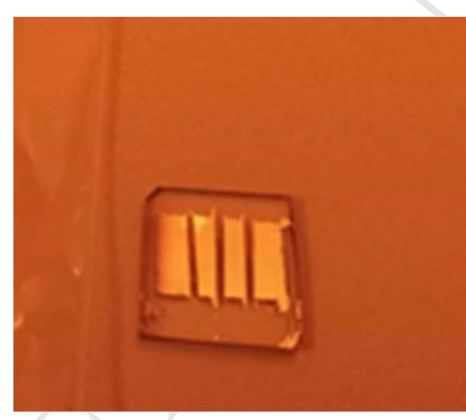

Figure S6 (a) Illustration of LRG conductivity measurement procedure. (b) The photograph of sample for conductivity test

$\mathrm{R}$

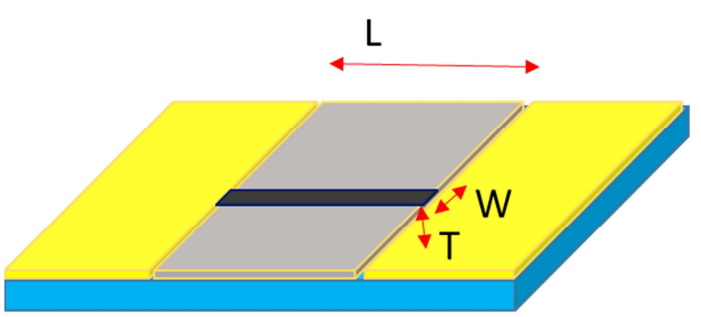

$$
\begin{aligned}
R=\rho \frac{L}{S} & \Rightarrow \rho=\frac{R S}{L} \\
& \Rightarrow \sigma=\frac{1}{\rho}=\frac{L}{R S}=\frac{L}{R W T}
\end{aligned}
$$

Figure S7 Graphic illustration of the calculative method for LRG conductivity (L,length of LRGO; W, width of LRGO; T, thickness of LRGO; S, the area of LRGO) 
Table S7 Conductivities of LRGO with different scanning speeds at power of $5 \mathrm{~mW}$

\begin{tabular}{|c|c|c|c|c|c|c|c|}
\hline Scanning & Energy & Resistance & Resistance & $\mathbf{L}$ & W & $\mathbf{T}$ & Conductivity \\
\hline \multirow[t]{2}{*}{ speed } & density & before laser & after laser & & & & \\
\hline & & irradiation & irradiation & & & & \\
\hline$(\mu \mathrm{m} / \mathbf{s})$ & $\left(\mathrm{mJ} / \mu \mathrm{m}^{2}\right)$ & $(\mathrm{M} \Omega)$ & $(\mathrm{M} \Omega)$ & $(\mu \mathrm{m})$ & $(\mu \mathrm{m})$ & $(\mathrm{nm})$ & $(\mathrm{S} / \mathrm{m})$ \\
\hline 2 & 1.25 & 480 & 353 & 688 & 1.06 & 97 & 19.0 \\
\hline 1 & 2.5 & 510 & 108 & 502 & 1.31 & 96 & 36.9 \\
\hline 0.5 & 5 & 1000 & 125 & 647 & 1.81 & 93 & 30.7 \\
\hline 0.2 & 12.5 & 505 & 110 & 694 & 2.42 & 73 & 35.7 \\
\hline 0.1 & 25 & 700 & 61 & 640 & 3.25 & 71 & 45.5 \\
\hline
\end{tabular}




\section{Accepted Manuscript}

Tuning the sub-processes in laser reduction of graphene oxide by adjusting the power and scanning speed of laser

Zhengfen Wan, Shujun Wang, Ben Haylock, Jasreet Kaur, Philip Tanner, David Thiel, Robert Sang, Ivan S. Cole, Xiangping Li, Mirko Lobino, Qin Li

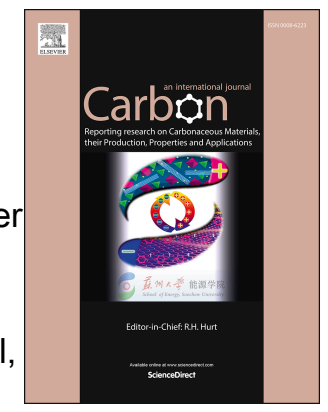

PII:

S0008-6223(18)30844-3

DOI:

10.1016/j.carbon.2018.09.030

Reference: CARBON 13458

To appear in: Carbon

Received Date: 19 June 2018

Revised Date: 31 August 2018

Accepted Date: 8 September 2018

Please cite this article as: Z. Wan, S. Wang, B. Haylock, J. Kaur, P. Tanner, D. Thiel, R. Sang, I.S. Cole, $X$. Li, M. Lobino, Q. Li, Tuning the sub-processes in laser reduction of graphene oxide by adjusting the power and scanning speed of laser, Carbon (2018), doi: 10.1016/j.carbon.2018.09.030.

This is a PDF file of an unedited manuscript that has been accepted for publication. As a service to our customers we are providing this early version of the manuscript. The manuscript will undergo copyediting, typesetting, and review of the resulting proof before it is published in its final form. Please note that during the production process errors may be discovered which could affect the content, and all legal disclaimers that apply to the journal pertain. 


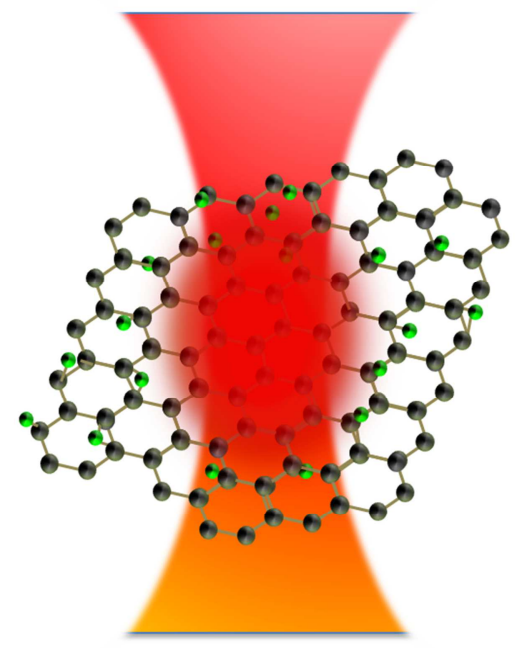

Laser reduction of graphene oxide
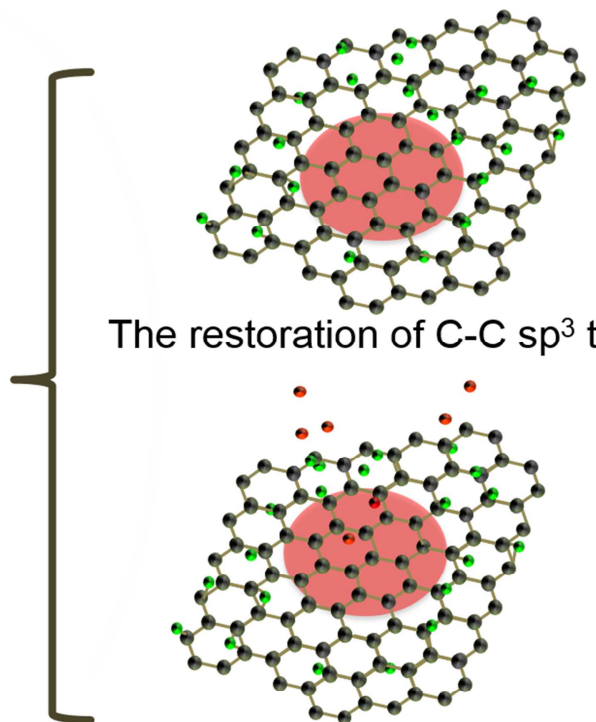

The restoration of $\mathrm{C}-\mathrm{C} s \mathrm{sp}^{3}$ to $\mathrm{C}-\mathrm{C} \mathrm{sp}^{2}$

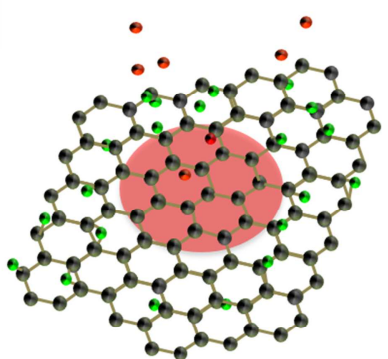

The removal of oxygen groups 